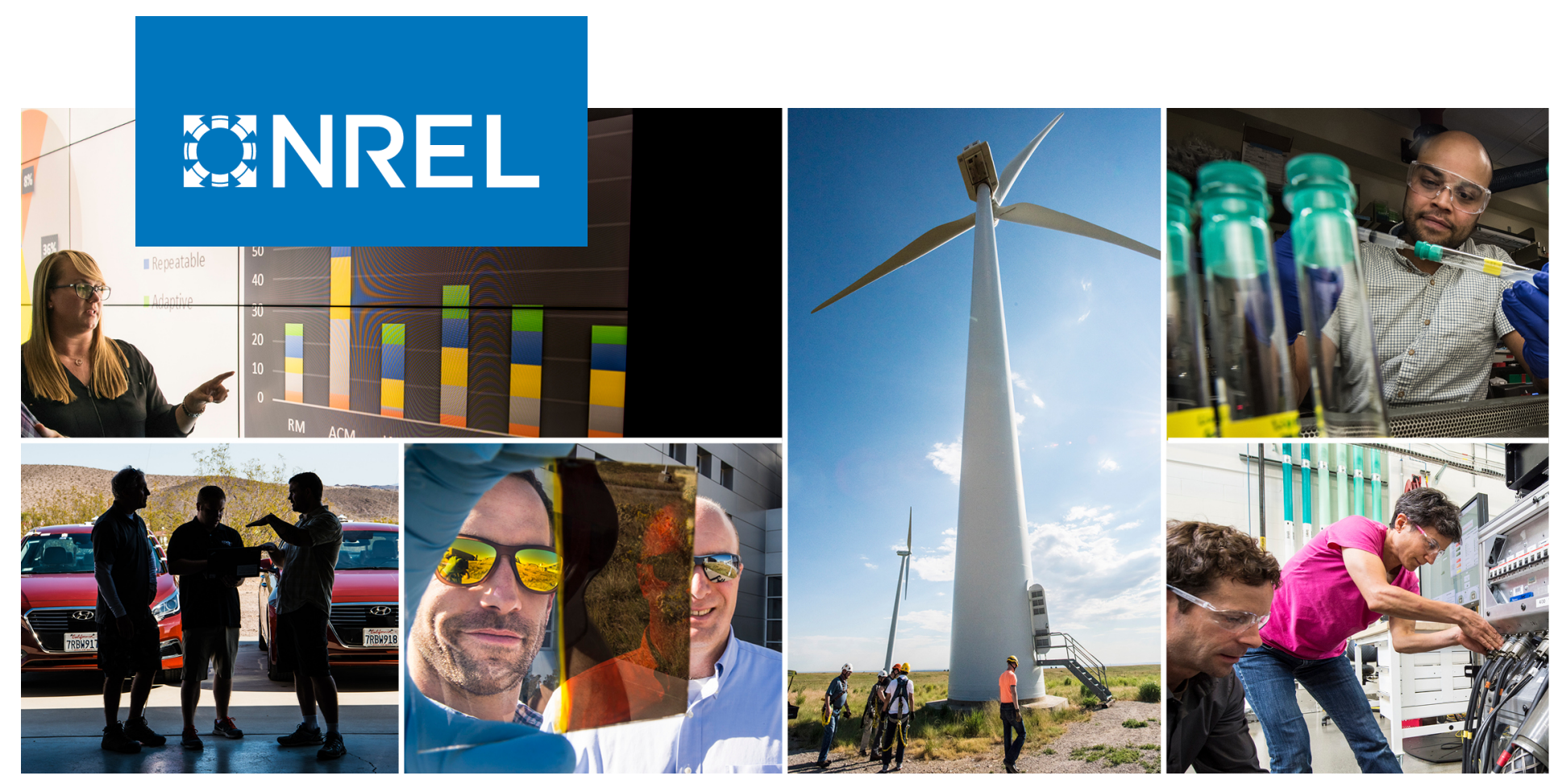

\title{
Analysis of Fault Data Collected from Automated Fault Detection and Diagnostic Products for Packaged Rooftop Units
}

Gregory Shoukas, Marcus Bianchi, and Michael Deru

National Renewable Energy Laboratory

NREL is a national laboratory of the U.S. Department of Energy Office of Energy Efficiency \& Renewable Energy

Operated by the Alliance for Sustainable Energy, LLC

This report is available at no cost from the National Renewable Energy Laboratory (NREL) at www.nrel.gov/publications.
Technical Report

NREL/TP-5500-77077

September 2020 


\section{GNREL}

\section{Analysis of Fault Data Collected from Automated Fault Detection and Diagnostic Products for Packaged Rooftop Units}

Gregory Shoukas, Marcus Bianchi, and Michael Deru

National Renewable Energy Laboratory

\section{Suggested Citation}

Shoukas, Gregory, Marcus Bianchi, and Michael Deru. 2020. Analysis of Fault Data Collected from Automated Fault Detection and Diagnostic Products for Packaged Rooftop Units. Golden, CO: National Renewable Energy Laboratory. NREL/TP-5500-77077.

https://www.nrel.gov/docs/fy20osti/77077.pdf.

NREL is a national laboratory of the U.S. Department of Energy Office of Energy Efficiency \& Renewable Energy Operated by the Alliance for Sustainable Energy, LLC

This report is available at no cost from the National Renewable Energy Laboratory (NREL) at www.nrel.gov/publications.

Contract No. DE-AC36-08GO28308
Technical Report

NREL/TP-5500-77077

September 2020

National Renewable Energy Laboratory 15013 Denver West Parkway Golden, CO 80401

303-275-3000 • www.nrel.gov 


\section{NOTICE}

This work was authored by the National Renewable Energy Laboratory, operated by Alliance for Sustainable Energy, LLC, for the U.S. Department of Energy (DOE) under Contract No. DE-AC36-08GO28308. Funding provided by U.S. Department of Energy Office of Energy Efficiency and Renewable Energy Building Technologies Office. The views expressed herein do not necessarily represent the views of the DOE or the U.S. Government.

This report is available at no cost from the National Renewable Energy Laboratory (NREL) at www.nrel.gov/publications.

U.S. Department of Energy (DOE) reports produced after 1991 and a growing number of pre-1991 documents are available free via www.OSTI.gov.

Cover Photos by Dennis Schroeder: (clockwise, left to right) NREL 51934, NREL 45897, NREL 42160, NREL 45891, NREL 48097, NREL 46526.

NREL prints on paper that contains recycled content. 


\section{Acknowledgments}

The authors would like to thank the different organizations that volunteered data sets and information to be analyzed in this report. Thanks to Miles Hayes of the National Renewable Energy Laboratory for assisting in the outreach to the industry partners and initial analysis of the data sets.

For more information, contact:

Gregory Shoukas

National Renewable Energy Laboratory

Email: gregory.shoukas@,nrel.gov 


\section{List of Acronyms}

AFDD

BMS

DOE

HVAC

NREL

RTU

VFD automated fault detection and diagnostics

building management system

U.S. Department of Energy

heating, ventilating, and air conditioning

National Renewable Energy Laboratory

rooftop unit

variable frequency drive 


\section{Executive Summary}

Rooftop units (RTUs) and other packaged systems are very common in commercial buildings in the U.S., and they often have minimal controls and poor performance. Automated fault detection and diagnostics (AFDD) is a powerful tool that can continuously monitor operating equipment, detect abnormal performance, diagnose problems, and report findings to building operators. AFDD technologies for RTUs have been under development for many years and have recently begun to enter the market in a significant way. There are several AFDD systems available for RTUs that feature a wide range of designs, capabilities, and reporting. Unfortunately, there is little consistency among the AFDD applications and little understanding of the performance and value of these systems.

This study presents analysis of AFDD data provided by four companies from over 28,000 RTUs, five building types, and multiple climate zones. The objectives of this investigation were to gain a better understanding of how RTU AFDD systems operate, the types and frequencies of faults identified, and how building operators interact with these systems. The monitoring of a variety of RTUs provides insights into the AFDD monitoring inputs, faults, and diagnostics from which these tools are capable of informing building owners about the status of their HVAC systems.

The project team encountered two major challenges with AFDD data collection and analysis. The first challenge to sharing data included privacy and intellectual property concerns, data formats and storage media that could not be shared, lack of staff availability to process and share data, and lack of interest in participating in the project, which severely reduced the amount of data included in the project. Differences in data formats, fault definitions, fault diagnostics, and fault reporting made compiling and comparing data nearly impossible and results are presented separately for each participating company.

Fault frequency reported by different AFDD systems depends greatly on fault definitions. Economizer faults were the most common fault from the first AFDD company representing faults in $10 \%, 26 \%$, and $29 \%$ of the RTU operating time in three different building types. The economizer faults were determined based on comparing the calculated air flow with an expected air flow. Heating and cooling operation faults were the next most common faults from this company. The second and third AFDD companies provided their services to the same small-box retailer and they reported sensor failure and communication failures as the most common faults. Most of these sensor failure faults were not sensor failures but were instances when space temperature and relative humidity values were outside of the setpoint values. Communication faults include moments of lost communications; however, information is usually not lost due to storage at the controller level. Cooling system faults represented $57 \%$ of the faults reported by the final AFDD company.

Several observations and recommendations were developed to improve performance of AFDD systems. For best results, AFDD systems should track historical performance and be linked to asset and maintenance management systems to streamline trouble shooting, repair, and replacement efforts. Fault reporting should be concise and provide actionable information and if possible, prioritize faults based on economic impact. Standard fault definitions and reporting would help overcome several barriers to deployment and significantly improve market acceptance and comparisons of AFDD systems. 


\section{Table of Contents}

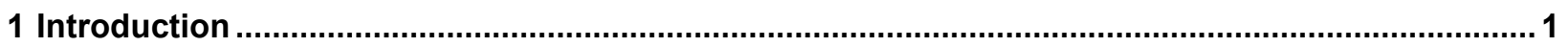

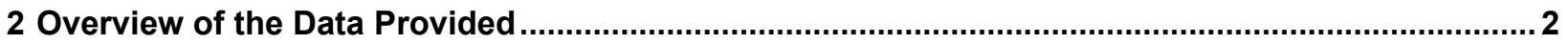

2.1 Company-A, Automated Fault Detection and Diagnostics Data Set 1-Quick Serve Restaurant .. 3

2.2 Company-A, Automated Fault Detection and Diagnostics Data Set 2 - Pharmacy................... 4

2.3 Company-A, Automated Fault Detection and Diagnostics Data Set 3-Clothing Retailer .......... 4

2.4 Company-B, Automated Fault Detection and Diagnostics Data Set 1-Small-Box Retail Stores.. 6

2.5 Company-C, Automated Fault Detection and Diagnostics Data Set 1-Small-Box Retail Stores.. 7

2.6 Company-D, Previously Summarized Data Sets........................................................ 7

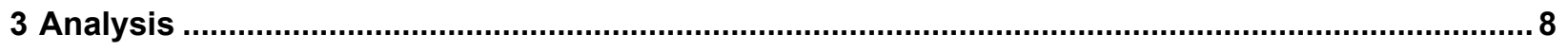

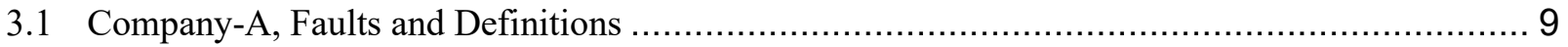

3.1.1 Analysis Company-A, Quick Serve Restaurant …...........................................11

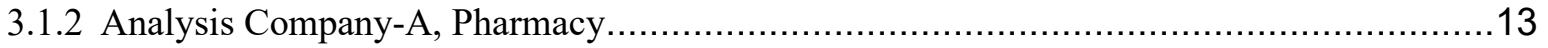

3.1.3 Analysis Company-A, Clothing Retail Facilities .................................................

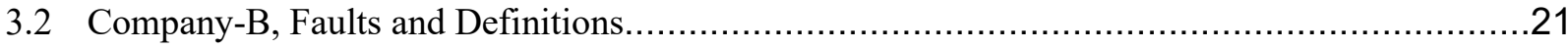

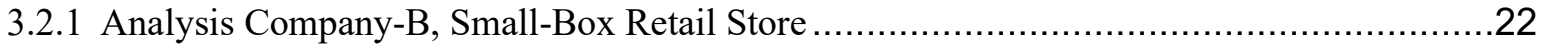

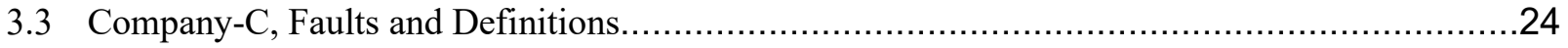

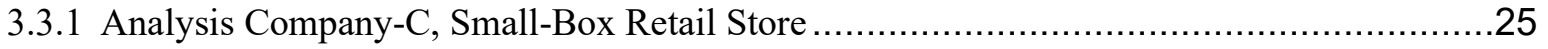

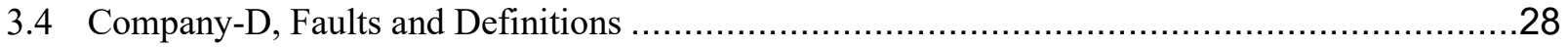

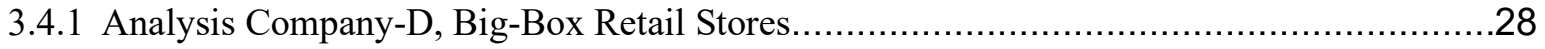

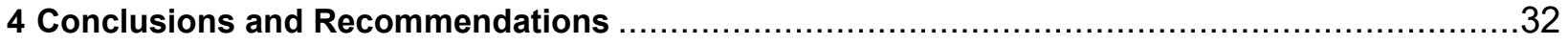

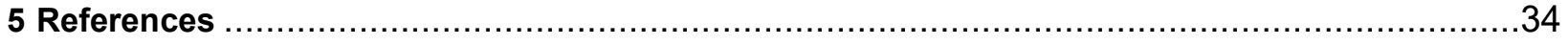

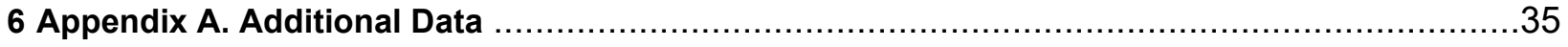




\section{List of Figures}

Figure 1. Distribution of sites per number of rooftop units monitored at the pharmacy sites ..................... 4

Figure 2. Distribution of sites per number of rooftop units monitored at the clothing retail stores............. 6

Figure 3. Fault hours per 1,000 hours of operation for the quick serve restaurants............................... 11

Figure 4. Advanced economizer faults detailing the quick serve restaurant damper faults ...................... 12

Figure 5. Consecutive days of reported economizer faults for the quick serve restaurant ....................... 13

Figure 6. Fault hours per 1,000 hours of operation for rooftop units at the pharmacy sites ...................... 14

Figure 7. Percent of time rooftop units reported fault-free operation at the pharmacy sites..................... 15

Figure 8. Consecutive days of reported economizer faults at the pharmacy sites ................................... 16

Figure 9. Fault hours per 1,000 hours of operation for rooftop units at the clothing retail sites................ 17

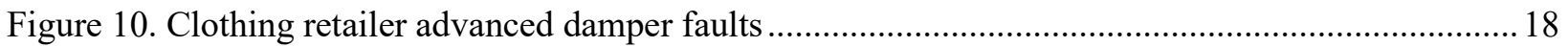

Figure 11. Fault hours per 1,000 hours of operation for rooftop units with economizers based on climate

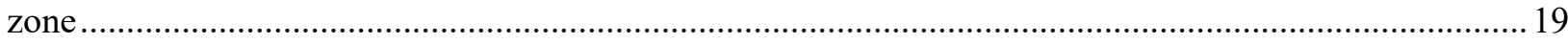

Figure 12. Fault hours per 1,000 hours of operation for rooftop units without economizers based on

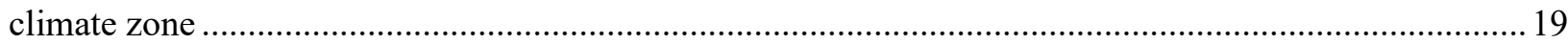

Figure 13. Percent of time rooftop units reported fault-free operation at the clothing retail store sites ..... 20

Figure 14. Consecutive days of reported economizer faults at the retail store sites ...............................2 21

Figure 15. Frequency of the number faults at 371 sites reported by Company-B .................................2 23

Figure 16. Fault frequency for rooftop units at small-box retail stores ................................................2

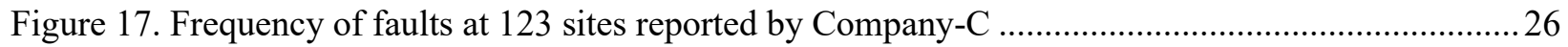

Figure 18. Fault frequency for rooftop units at small-box retail stores ................................................27

Figure 19. Fault frequency by percent for rooftop units at the big-box retail stores ...............................29

Figure 20. Number of rooftop units and the percentage of faults detected from the RTUs in each of the

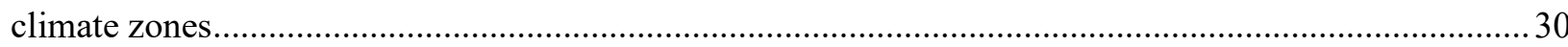

Figure 21. Number of rooftop units in four climate zones binned by age .............................................30

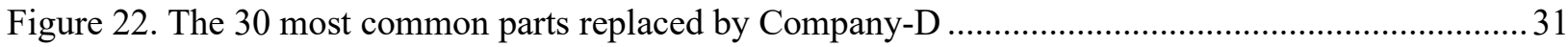

Figure A-1. IECC Climate Zone Map (ASHRAE 2013) ...................................................................... 35 


\section{List of Tables}

Table 1. Rooftop Unit Automated Fault Detection and Diagnostics Data Sources ................................... 2

Table 2. Number of Rooftop Units at the Clothing Retail Sites by Climate Zone...................................... 5

Table 3. Number of Buildings by Climate Zone Monitored by Company-B .......................................... 6

Table 4. Number of Buildings by Climate Zone Monitored by Company-C .......................................... 7

Table 5. Number of Rooftop Units for the Big-Box Retail Stores by Climate Zone.................................. 8

Table 6. Rooftop Unit Automated Fault Detection and Diagnostics Fault Categories ............................... 8

Table 7. Faults from Company-A Categorized Based on Fault Type ..................................................... 9

Table 8. Advanced Economizer Faults that Detail the Nature of a Reported Automated Fault Detection

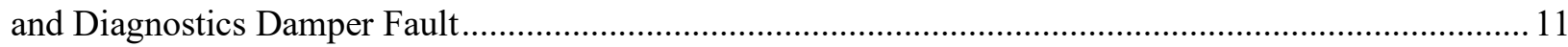

Table 9. Reported Building Management System and Rooftop Unit Control Board Faults by Company-B

Table 10. Reported Building Management System and Rooftop Unit Control Board Faults by Company-C

Table A-1. Distribution of Rooftop Unit Capacity at the Pharmacy Sites ............................................. 36

Table A-2. Distribution of Rooftop Unit Capacity at the Clothing Retail Sites ....................................... 37 


\section{Introduction}

In 2018, buildings accounted for about $40 \%$ of total U.S. energy consumption (EIA 2019). Of the electrical energy used in commercial buildings, about $15 \%$ is for space cooling (EIA 2012). Rooftop units (RTUs) are the most common type of heating, ventilating, and air-conditioning (HVAC) system in U.S. commercial buildings (EIA 2012). They often operate with one or more faults due to poor maintenance, degradation, and improper control (Katipamula and Brambley 2005).

Automated fault detection and diagnostics (AFDD) is a powerful tool that can continuously monitor operating equipment, detect abnormal performance, diagnose problems, and report findings to building operators. AFDD technologies for RTUs have been under development for many years and have recently begun to enter the market in a significant way. There are several AFDD systems available for RTUs that feature a wide range of designs, capabilities, and reporting. Unfortunately, there is little consistency among the AFDD applications and little understanding of the performance and value of these systems.

In a previous National Renewable Energy Laboratory (NREL) report, Wheeler et al. (2020) documented the capabilities of RTU AFDD systems currently offered by manufacturers and how RTU AFDD is being used today by building owners, based on primary data collected from industry representatives.

There have been studies on the effectiveness of individual RTU AFDD systems for detecting faults and the predicted impact of fault detection (Heinemeier 2012); however, there have been no large-scale studies on the installed performance of AFDD systems and the faults detected by these systems. The objectives of the present investigation are to gain a better understanding of how RTU AFDD systems operate, the types and frequencies of faults identified, and how building operators interact with these systems. To achieve these objectives, we requested AFDD data from several AFDD providers and building owners with the intent of covering a variety of AFDD systems, building types, and locations. Although collecting data was more challenging than anticipated, we were able to obtain data from four AFDD systems, five building types, multiple locations, and more than 25,000 RTUs. Collecting and analyzing data from multiple sources was challenging because of the minimal information provided, variety of data formats, and lack of standardized fault definitions. Most AFDD systems are customized for the customers' unique applications, which provides solutions that fit with building owners' needs but also increases overall costs and limits the broad application and usefulness of AFDD systems. These results support the need for a standardized fault taxonomy (Frank et al. 2019) and reporting format for better uniformity across the industry.

The subsequent sections of this report are structured as follows:

- Section 2 provides an overview of the data collection process and data provided

- Section 3 analyzes the types and frequencies of reported faults

- Section 4 summarizes the findings and provides recommendations. 


\section{Overview of the Data Provided}

We used the work completed by Wheeler et al. (2020) to develop a list of AFDD providers and building owners applying AFDD monitoring tools to their RTUs. In preparation to meet the objectives of this project, we developed a data collection plan with identified data sources and a framework for data collection. We identified five AFDD providers and five building owners representing more than 60,000 RTUs across the country that we contacted to share data for this project. Most of the groups contacted were interested in the project but several challenges limited the amount of available data. Barriers to sharing data included privacy and intellectual property concerns, data formats and storage media that could not be shared, lack of staff availability to process and share data, and lack of interest in participating in the project. One building owner requested a nondisclosure agreement before sharing data, one AFDD vendor provided detailed data from three building owners, one AFDD vendor provided a summary of AFDD results, and two building owners provided high-level summaries. The final data received was in various formats with different fault definitions, making analysis time-consuming and challenging to summarize across all projects.

The five data sets provided to NREL were from three companies that monitor AFDD. A fourth company provided a summary of the AFDD information from their own analysis. This report refers to them as Company-A, Company-B, Company-C, and Company-D as summarized in Table 1.

Table 1. Rooftop Unit Automated Fault Detection and Diagnostics Data Sources

\begin{tabular}{|l|c|c|c|c|c|}
\hline Data Source & Building Types & $\begin{array}{c}\text { Regions } \\
\text { /Locations }\end{array}$ & Dates & $\begin{array}{c}\text { Number of } \\
\text { Sites }\end{array}$ & $\begin{array}{c}\text { Number of } \\
\text { RTUs }\end{array}$ \\
\hline Company-A & $\begin{array}{c}\text { Quick serve } \\
\text { restaurants }\end{array}$ & New York City & $\begin{array}{c}\text { Jan 1, 2019- } \\
\text { Nov 26, 2019 }\end{array}$ & 5 & 15 \\
\hline Company-A & Pharmacy & $\begin{array}{c}\text { Washington } \\
\text { State }\end{array}$ & $\begin{array}{c}\text { Jan 1, 2019- } \\
\text { Nov 26, 2019 }\end{array}$ & 42 & 133 \\
\hline Company-A & Clothing retailer & U.S. & $\begin{array}{c}\text { Jan 2019-Sept } \\
2019\end{array}$ & 330 & 1,689 \\
\hline Company-B & Small-box retailer & U.S. & $\begin{array}{c}\text { Dec 2018-Dec } \\
2019\end{array}$ & 371 & unknown \\
\hline Company-C & Small-box retailer & U.S. & 1 week & 123 & unknown \\
\hline Company-D & Big-box retailer & U.S. & $2013-2018$ & 1733 & 25,800 \\
\hline
\end{tabular}

Company-A uses an "off-the-shelf” retrofit AFDD system that continuously monitors the status of the RTU and controls the equipment. The retrofit controllers ${ }^{1}$ require minimal customization during installation and collect measured values via their installed sensors. Through real-time detection and diagnostics on the controller, the faults are communicated to the building owner via email as well as a web-based portal. The email summarizes the fault trigger, the time of the

\footnotetext{
${ }^{1}$ Company-A's controller is an aftermarket measurement and control device that is spliced between the zone sensor and the existing RTU controller provided by the manufacturer. Their controller intercepts the signals from the zone sensor and, based on its own control logic, sends commands to the existing RTU controller. It provides operational control algorithms to the RTU and monitors the status of the sensors and systems.
} 
fault, and the potential causes. The three data sets provided by Company-A contained structured fault categories that were easy to understand and analyze using a spreadsheet. These sets contained information about the heating, cooling, and economizer features in each of the RTUs being monitored. For each fault category, which are detailed in Section 3.1, the data set reported a daily summary with the number of hours the system detected each fault. No information regarding corrective action with respect to the faults is noted in any of these data sets. There were some variations between the three sets that will be discussed in Section 3. Due to the variability in the number of daily reports per RTU, we normalized the AFDD data per 1,000 hours of operating time.

Companies-B and -C provided AFDD data for the same building owner but at different sites. These AFDD systems tie into the existing building management system (BMS) and use RTU and building sensors and RTU on-board fault detection. Company-B and Company-C data sets contained information that had numerous inconsistencies, conflicting details, and gaps in their record structure. Significant numbers of redundant entries were removed prior to analyzing the fault frequency. These sets have no information on equipment features, specifications, or age. No economizer damper faults or airside issues were reported. The fault records are provided to a regional repair team contact, who initiates a service request. These sets include building operator notes on work orders submitted. Although Company-B and Company-C monitor RTUs within the same small-box retailer's buildings portfolio, the AFDD data sets present different reporting formats and informational content.

Company-D has a cloud-based product that gathers data from the RTUs, controllers, and sensors by connecting to the existing BMS. Because the information is provided by the BMS, this approach is RTU and controller agnostic. Through various software connection options into the BMS, data can be pushed or pulled for cloud based AFDD fault analysis. Instead of providing raw data to analyze, they supplied a summary of the information aggregated over 6 years. The summary contained typical fault types, repairs common to those faults, and the frequency of occurrences. Company-D monitors more than 60 anomalies and categorizes them into cooling, heating, economizer/damper, sensor, or communication faults.

\subsection{Company-A, Automated Fault Detection and Diagnostics Data Set 1-Quick Serve Restaurant}

This is the smallest of three data sets from Company-A, containing AFDD faults from 15 RTUs located in five quick serve restaurants located in New York City. The data set provides detailed information about each of the sites, which contain as many as six RTUs ranging in capacity from three to 20 tons. The make and model of the RTUs are also available, but the ages of the units were not provided. All RTUs have economizers and the AFDD monitoring data contain an additional set of advanced economizer fault information that better explains the nature of the damper faults. In addition, the retrofit controllers have variable frequency drives (VFD) to the supply fans, converting them from constant speed to multispeed operation. All the RTUs have gas fired heating.

Each of the 15 RTUs has a daily summary report from Jan. 1 through Nov. 26, 2019. For each day, the report contains the number of hours during which the AFDD system detected abnormal 
operating behavior from the RTU. This data set provides 4,920 RTU-days of AFDD data from which we evaluated trends and determined the frequency of fault occurrences.

\subsection{Company-A, Automated Fault Detection and Diagnostics Data Set 2-Pharmacy}

This data set from Company-A contains AFDD faults from 133 RTUs located at 42 pharmacy sites in Washington State. The data set provides detailed information about the sites, each of which has two to six RTUs ranging in capacity from two tons to 20 tons. The make and model of the RTUs are also available, but the ages of the units were not provided. All RTUs have economizers except for 19 units located at 11 sites. These data sets do not contain the more detailed advanced economizer fault information for the units with economizers because Company-A installed these sites before they had developed advanced economizer AFDD algorithms. From the 133 RTUs, one unit uses electric heat, ten units are heat pumps, and 122 units have gas fired heating. Figure 1 displays the distribution of sites based on the number of RTUs installed. Most sites (29 of the 42 sites) monitor three RTUs.

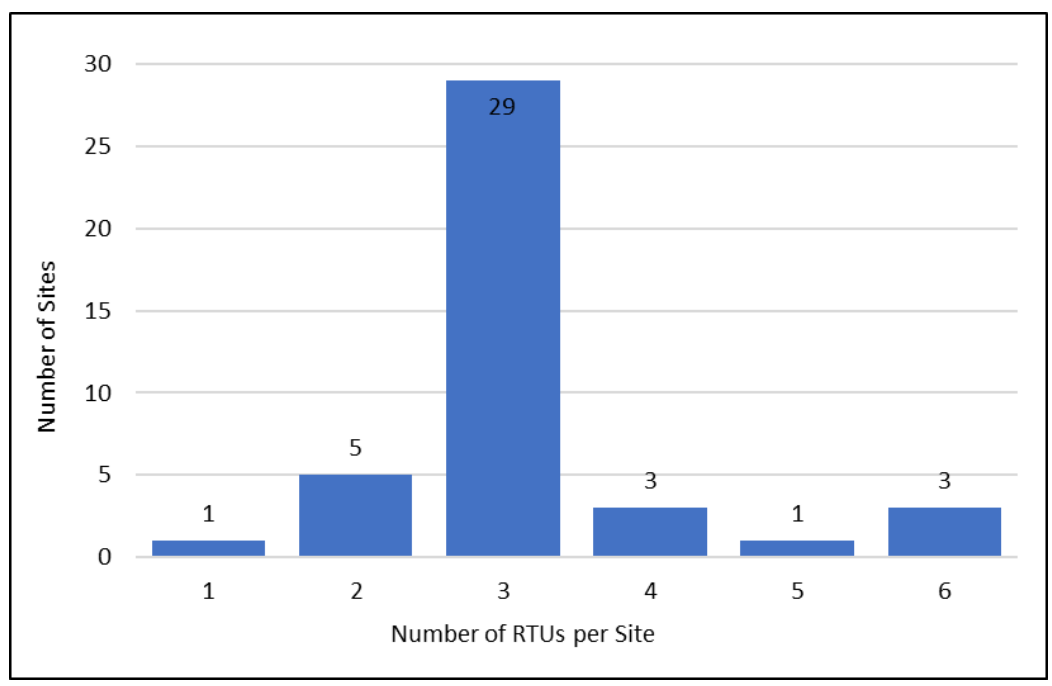

Figure 1. Distribution of sites per number of rooftop units monitored at the pharmacy sites

Each of the 133 RTUs has a daily summary report from Jan. 1 through Nov. 26, 2019. This data set provides 43,624 RTU-days of AFDD data from which we evaluated trends and determined the frequency of fault occurrences.

\subsection{Company-A, Automated Fault Detection and Diagnostics Data Set 3-Clothing Retailer}

The last data set from Company-A contains AFDD faults from 1,851 RTUs located at 360 clothing retail sites in seven IECC climate zones (see Figure A-1). The data were collected between January and September of 2019. Each store contains up to 16 RTUs ranging in capacity from 3.5 to 125 tons. The data set provides detailed information about each of the sites. The make and model of the RTUs are available in most instances, but the ages of the units were not provided. 
Some RTUs in this data set had as little as 12 days of records while others had up to 273 days of fault data. We decided to evaluate only the RTUs that had more than 120 days of data to have statistically significant comparisons of fault frequency. From the original data set that contained 1,851 RTU, we evaluated 1,689 RTUs located at 330 sites (409,199 RTU-days):

- 1,301 units have economizers, for which the more detailed advanced economizer fault information is available.

- 439 units provide electric heat, 446 units are heat pumps, 763 units have gas fired heating, and 41 units have no heating ability.

Table 2 shows the number of RTUs in each of the IECC climate zones, including information about economizers.

Table 2. Number of Rooftop Units at the Clothing Retail Sites by Climate Zone

\begin{tabular}{|c|c|c|}
\hline Climate Zone $^{2}$ & $\begin{array}{c}\text { RTUs with } \\
\text { Economizers }\end{array}$ & $\begin{array}{c}\text { RTUs without } \\
\text { Economizers }\end{array}$ \\
\hline 1 & 34 & 12 \\
\hline 2 & 200 & 57 \\
\hline 3 & 364 & 191 \\
\hline 4 & 247 & 55 \\
\hline 5 & 390 & 57 \\
\hline 6 & 66 & 12 \\
\hline 7 & 0 & 4 \\
\hline
\end{tabular}

Figure 2 displays the distribution of sites per number of RTUs installed.

${ }^{2}$ Locations for the seven ASHRAE climate zones can be found in Figure A-1 of the appendix. 


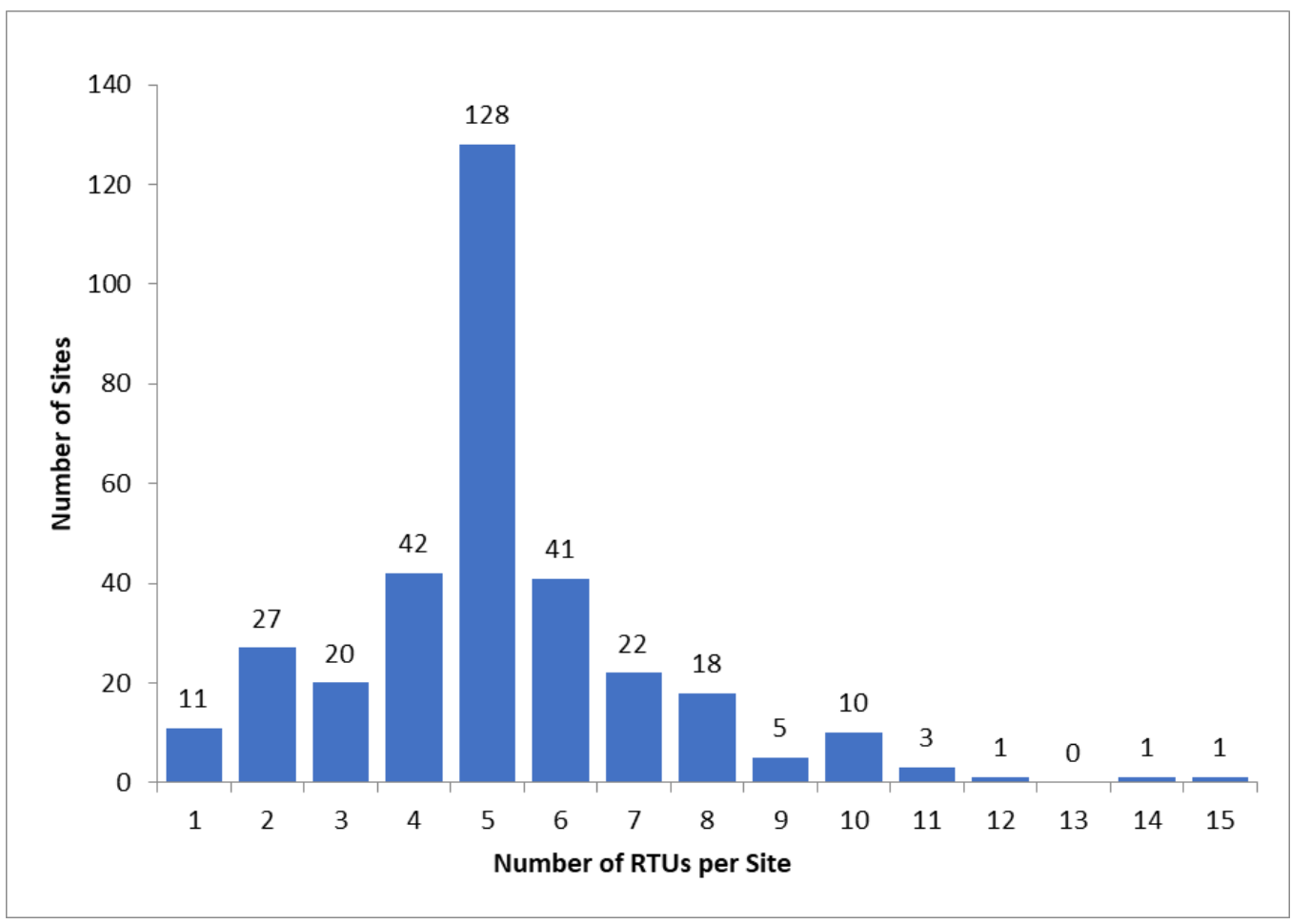

Figure 2. Distribution of sites per number of rooftop units monitored at the clothing retail stores

\subsection{Company-B, Automated Fault Detection and Diagnostics Data Set 1-Small-Box Retail Stores}

This data set contains 13 months of AFDD data. Although information such as dates, times, building locations, and faults are reported in a semiorganized structure, the AFDD records lacked consistency and uniformity. There were missing data, conflicting entries, and improper characterization of the fault categories that required significant effort to correct and gap fill to extract a more accurate summary. A complete list of the sites and RTU portfolio was not provided, and fault incidences were reported as they occur, so we are only aware of the monitored equipment based on an associated fault record. It is uncertain if all equipment revealed in the fault records were monitored for the entire year or part of it. This data set contains 371 sites located in seven IECC climate zones as shown in Table 3.

Table 3. Number of Buildings by Climate Zone Monitored by Company-B

\begin{tabular}{|c|c|}
\hline Climate Zone & Number of Sites \\
\hline 1 & 6 \\
\hline 2 & 72 \\
\hline 3 & 98 \\
\hline 4 & 75 \\
\hline 5 & 89 \\
\hline 6 & 27 \\
\hline 7 & 4 \\
\hline
\end{tabular}


There is no information regarding the RTUs' make and model, capacity, or age. No economizer faults were reported despite the existence of some units with capabilities to monitor the damper status on the RTU control board. Appended onto existing fault records, manually entered notes regarding submitted work orders with progress and remaining issues are available, but difficult to follow. Some of the notes referenced faults and unresolved issues several months prior without clear details to properly understand them.

\subsection{Company-C, Automated Fault Detection and Diagnostics Data Set 1-Small-Box Retail Stores}

This data set contains 1 week of data. Information such as building location and fault are reported in a semiorganized structure, but the fault data lack uniformity and consistency. There were missing data, conflicting entries, and improper characterizations. The detailed information needed to be parsed into additional categories to effectively sort and summarize the data set. Company-C and Company-B monitor RTUs at different sites of the same chain of small-box retail stores. A complete list of sites and RTUs was not provided. Fault incidences are reported as they occur, therefore, we are only aware of equipment that has generated a fault record. This data set contains records from 123 sites in six IECC climate zones as is shown in Table 4.

Table 4. Number of Buildings by Climate Zone Monitored by Company-C

\begin{tabular}{|c|c|}
\hline Climate Zone & Number of Sites \\
\hline 1 & 4 \\
\hline 2 & 19 \\
\hline 3 & 37 \\
\hline 4 & 26 \\
\hline 5 & 31 \\
\hline 6 & 6 \\
\hline
\end{tabular}

There is no detailed information regarding the RTUs' make and model, capacity, or age. This AFDD system is capable of reading and reporting the built-in, control board faults from at least some of the RTUs. Although the RTU control boards can detect and generate economizer and airside faults, none were reported. The data set does include some records of submitted work orders demonstrating the unique capability for a building owner to report notes within their AFDD tool. Unfortunately, this information was not used. Multiple AFDD records contained identical work order numbers that were assigned and used at different buildings across the country. The ambiguity of the replicated work order data made further analysis impossible.

\subsection{Company-D, Previously Summarized Data Sets}

Company-D provided summarized information from the database they used to develop and refine better AFDD algorithms, but not the raw data for us to analyze. Their database contains more than 200 billion records from more than 33,000 RTUs collected during a 6-year period. On average, 40 data points per RTU are collected on a 15-minute interval allowing this rule and historical performance based AFDD system to assess at least 60 anomalies. 
Company-D provided a summary of that information representing more than 24,000 RTUs located in 1,733 sites, most of which are big-box retail stores. It represents typical fault categories and frequencies of RTUs of various capacities, manufacturers, ages, and climate zones. This summary provided a breakdown of the number of sites per IECC climate zone shown in Table 5.

Table 5. Number of Rooftop Units for the Big-Box Retail Stores by Climate Zone

\begin{tabular}{|c|c|}
\hline Climate Zone & Number of Sites \\
\hline 1 & 48 \\
\hline 2 & 296 \\
\hline 3 & 488 \\
\hline 4 & 418 \\
\hline 5 & 410 \\
\hline 6 & 68 \\
\hline 7 & 4 \\
\hline 8 & 1 \\
\hline
\end{tabular}

\section{Analysis}

The study authored by Wheeler et al. (2020) suggested seven categories into which AFDD faults could be grouped: economizer, airside, refrigerant, power, sensors, schedule, and zone cooling/heating. After evaluating the data provided by the four companies presented in this report, none of the AFDD faults were related specifically to refrigerant or schedule issues. Although power is monitored in certain AFDD systems, it is used as a measurement to identify faults in the categories listed in Table 6. Furthermore, all of them treat the status of the heating system separately from the cooling system. None of the data sets monitor the refrigerant system directly but they do report cooling faults related to set points that may be connected to improper refrigerant charge. All companies report device communication faults. In this analysis and when available, we present the data in the categories listed in Table 6. Other faults monitored by the four companies include indoor lighting, outdoor lighting, security system, and potable hot water temperature.

Table 6. Rooftop Unit Automated Fault Detection and Diagnostics Fault Categories

\begin{tabular}{|c|c|c|c|c|}
\hline Fault Category & Company-A & Company-B & Company-C & Company-D \\
\hline Cooling & $\mathrm{X}$ & $\mathrm{X}$ & $\mathrm{X}$ & $\mathrm{X}$ \\
\hline Heating & $\mathrm{X}$ & $\mathrm{X}$ & $\mathrm{X}$ & $\mathrm{X}$ \\
\hline Economizer & $\mathrm{X}$ & & & $\mathrm{X}$ \\
\hline Airside & $\mathrm{X}$ & $\mathrm{X}$ & & \\
\hline Sensor & $\mathrm{X}$ & $\mathrm{X}$ & $\mathrm{X}$ & $\mathrm{X}$ \\
\hline Communication & $\mathrm{X}$ & $\mathrm{X}$ & $\mathrm{X}$ & $\mathrm{X}$ \\
\hline Power/Phase & & $\mathrm{X}$ & $\mathrm{X}$ & \\
\hline Other & & $\mathrm{X}$ & $\mathrm{X}$ & \\
\hline
\end{tabular}


For the analysis of data provided by Company-A, the daily summary reports documented how many hours each fault was identified per day. The total number of days and hours were summed per fault. Additionally, the number of consecutive days was determined for the most prevalent damper faults to better understand how long a fault was continuously tallying hours and was not resolved. Due to one of the data sets not having a consistent number of RTU-days per piece of equipment being monitored, we decided to normalize the summed fault hours per 1000 hours of reported data.

Company-B and Company-C reported fault categories from Table 6 as they occurred. In addition to providing the fault category at the time of occurrence, the record also reported more detailed description of that fault. Fault categories were summed to provide the frequency of occurrences. The more detailed description was used in the analysis to better understand how the faults were categorized. This allowed us to accurately fill in missing fault category data and identify erroneous, inconsistent, or improperly categorized faults. With the detailed descriptions, we recognized that faults categorized by Company-B and Company-C were done differently than Company-A.

Company-D only provided summary information of their data from their own analysis. A raw data set was not provided, and we did not perform any analysis.

Due to the unique ways different company's identify anomalies and categorize these faults, it became clear that a data comparison between the companies would not be accurate. Section 3 will look at each of the data sets individually.

\subsection{Company-A, Faults and Definitions}

Company-A provided a list of AFDD faults that are reported in their daily logs. A list of their AFDD faults and descriptions are listed in Table 7. Their data set also includes the number of hours that the system was fault-free per day. All analysis using data sets from Company-A disregard the communication fault associated with offline hours. Since this fault is related to the communication loss between the retrofit controllers and the servers where the logged fault data is uploaded and archived it does not affect the operation of the RTU. Therefore, we decided these reported fault hours should not be included in the analysis related to the communication fault category.

Table 7. Faults from Company-A Categorized Based on Fault Type

\begin{tabular}{|l|l|l|}
\hline \multirow{2}{*}{ Fault Category } & Fault & Fault Description \\
\hline Cooling & Compressor & No power rise during a call for cooling \\
\cline { 2 - 3 } & Cooling & Reduced cooling capacity \\
\hline Ecating & Heating & Reduced heating capacity \\
\hline
\end{tabular}




\begin{tabular}{|c|c|c|}
\hline \multirow{4}{*}{ Airside } & Drive & VFD fails to follow the controller command \\
\hline & Fan Belt & $\begin{array}{l}\text { Abnormal fan (belt/sheave/alignment) } \\
\text { operation based on drive power }\end{array}$ \\
\hline & Drive Run & Fan not running when commanded \\
\hline & Supply Limit & Excessive supply air temperature condition \\
\hline \multirow{6}{*}{ Sensor } & $\mathrm{CO}_{2}$ & \multirow{6}{*}{ Out of range or broken sensor } \\
\hline & Current Transducer & \\
\hline & Outside Air Temperature & \\
\hline & Return Air Temperature & \\
\hline & Supply Air Temperature & \\
\hline & Space Temperature & \\
\hline \multirow{3}{*}{ Communication } & Drive Communication & $\begin{array}{l}\text { Interrupted controller/VFD drive } \\
\text { communication }\end{array}$ \\
\hline & Service Switch Off ${ }^{3}$ & Service switch set in the off position \\
\hline & Offline Hours ${ }^{4}$ & $\begin{array}{l}\text { Loss of communications with data servers } \\
\text { (hours not included in the fault analysis figures) }\end{array}$ \\
\hline
\end{tabular}

Descriptions of the advanced economizer faults reported in two of the data sets provided by Company-A are listed in Table 8. One or more of these detailed faults can accumulate fault hours per day however it cannot be determined from the data set if multiple advanced economizer faults can be reported at the same time.

\footnotetext{
${ }^{3}$ The Company-A Service Switch allows a technician to override the RTU into any mode of operation, including economizer modes, to verify proper operation. The switch was designed to save the technician time in having to jumper the terminal strip to verify proper operation.

${ }^{4}$ Offline hours are related to communications faults between the retrofit controllers and the servers where the logged fault data are uploaded for archiving purposes. This communication loss does not pertain to anomalies associated with the performance or operation of the RTU.
} 
Table 8. Advanced Economizer Faults that Detail the Nature of a Reported Automated Fault Detection and Diagnostics Damper Fault

\begin{tabular}{|l|l|}
\hline Advanced Economizer Fault & Fault Description \\
\hline Economizer Leaky & $\begin{array}{l}\text { Outside air damper commanded to minimum flow position, and the } \\
\text { calculated flow is greater than expected value }\end{array}$ \\
\hline Economizer Not Effective & $\begin{array}{l}\text { Outside air damper commanded to maximum flow position, and the } \\
\text { calculated flow is less than expected value }\end{array}$ \\
\hline Economizer Not Modulating & No economizer modulation \\
\hline Economizer Stuck Closed & $\begin{array}{l}\text { Economizer is not modulating, and the calculated airflow is less than } \\
\text { expected value }\end{array}$ \\
\hline Economizer Stuck Open & $\begin{array}{l}\text { Economizer is not modulating, and the calculated airflow is more than } \\
\text { expected value }\end{array}$ \\
\hline
\end{tabular}

\subsubsection{Analysis Company-A, Quick Serve Restaurant}

The evaluation of the normalized AFDD faults from 15 RTUs show significant time when the units had economizer faults. The fault condition hours per 1,000 hours of operation can be seen in the plot of Figure 3.

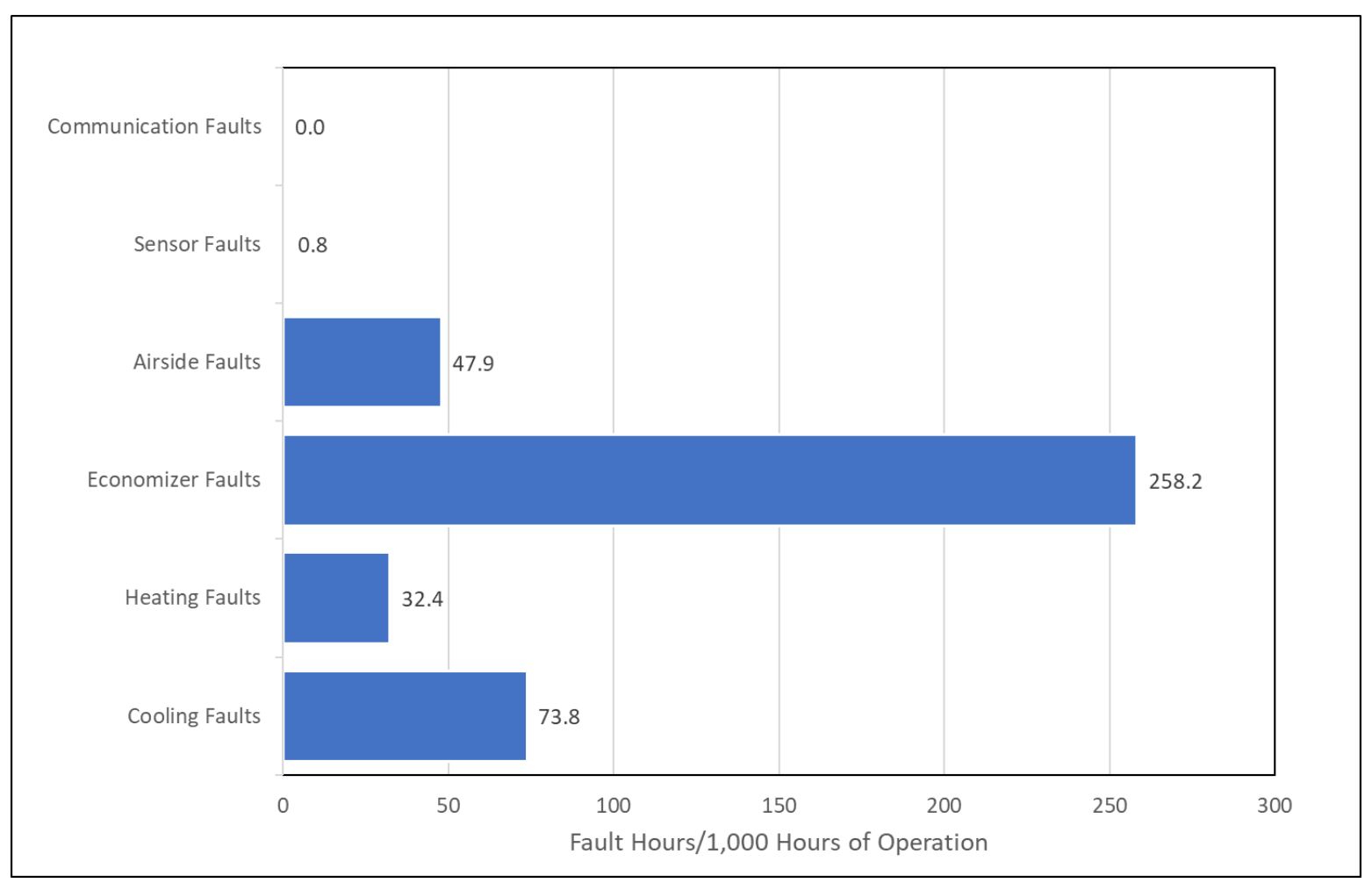

Figure 3. Fault hours per 1,000 hours of operation for the quick serve restaurants 
All units had economizers and the combined fault frequency was 258 hours per 1,000 operating hours. The significant amount of time associated with heating and cooling related faults could be a result of economizer dampers not operating correctly and imposing additional and excessive outside air loads on the RTUs' heating and cooling systems. A heating or cooling fault was also present $19 \%$ of the time when there was an economizer damper fault. The six sensors being monitored show high reliability and few failures or out of range faults.

A closer look at the advanced economizer fault data in Figure 4 shows that the primary cause of the damper faults are economizers allowing in less outside air than expected. Of the damper faults shown in Figure 3, 59\% of the time the outside airflow is less than expected, 24\% of the time the damper is not modulating properly, and $16 \%$ of the time the damper is stuck in the closed or minimum outside air position. Although the advanced economizer faults are helpful, no information is provided on how much the RTU deviates from an ideal set point or operation. Reporting information on the targeted set point and the measured value provides transparency in understanding the magnitude of the fault. The large number of damper faults if slightly out of bounds may have negligible impact on the operating performance of the RTU. By providing this information, a building owner may identify the fault severity and determine if they need to schedule an immediate service call or if it can be addressed during the next routine maintenance call.

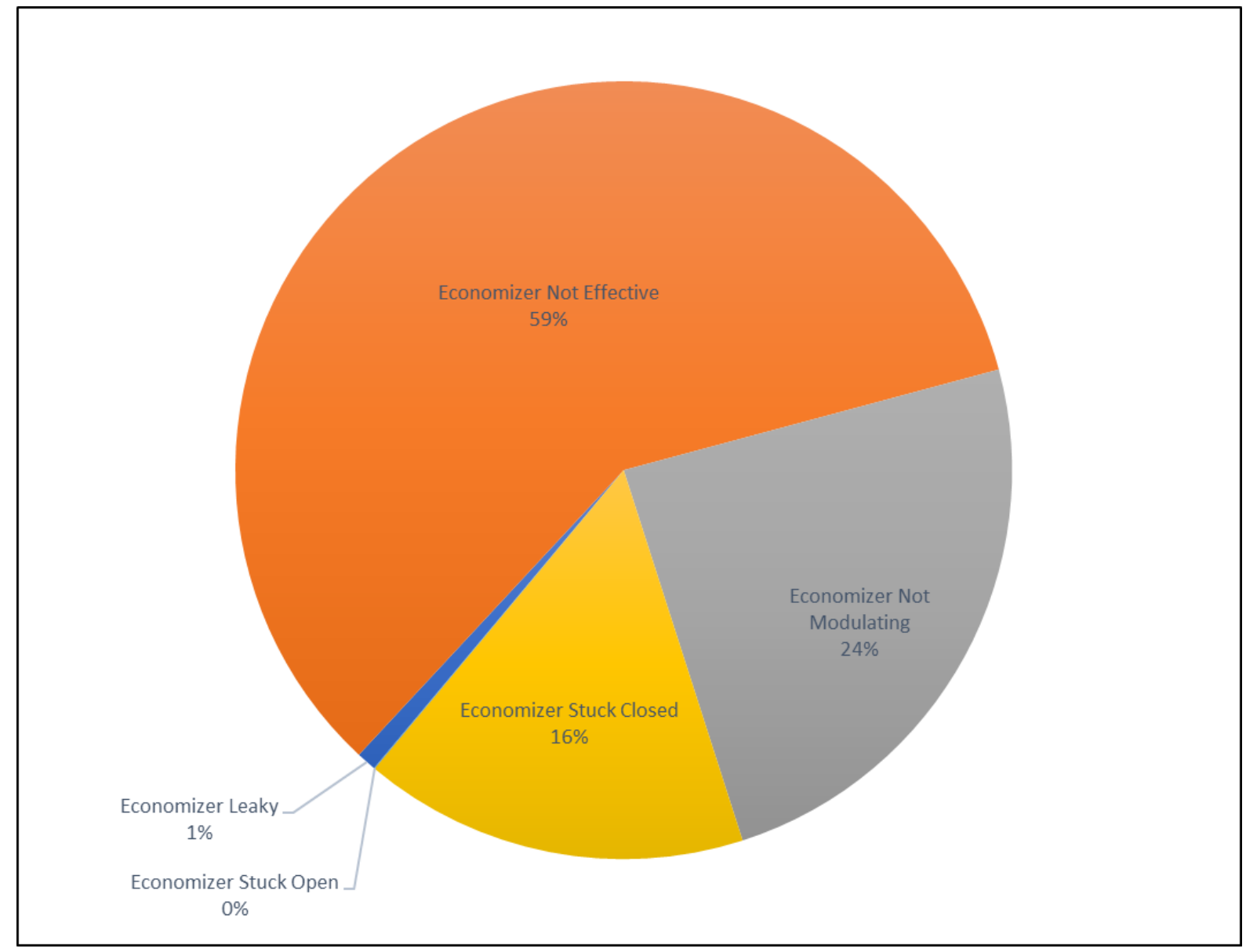

Figure 4. Advanced economizer faults detailing the quick serve restaurant damper faults 
Due to the large number of damper fault hours $(33,678$ RTU-hours), we examined the data set and realized that the problem resulted from a few RTUs that had many consecutive days of uncorrected faults. Figure 5 shows the maximum number of consecutive days the problematic RTUs had significant hours in damper faults. The bars represent the maximum number of consecutive days a unit was in fault, although additional consecutive days of damper faults may have occurred during the AFDD monitoring period. Nine of the 15 units had consecutive days of damper faults. Of those nine RTUs, six of them account for more than $70 \%$ of the total hours in fault. Two of the six reported damper faults for more than 120 consecutive days or three months. More than $98 \%$ of the damper faults are due to this group of units.

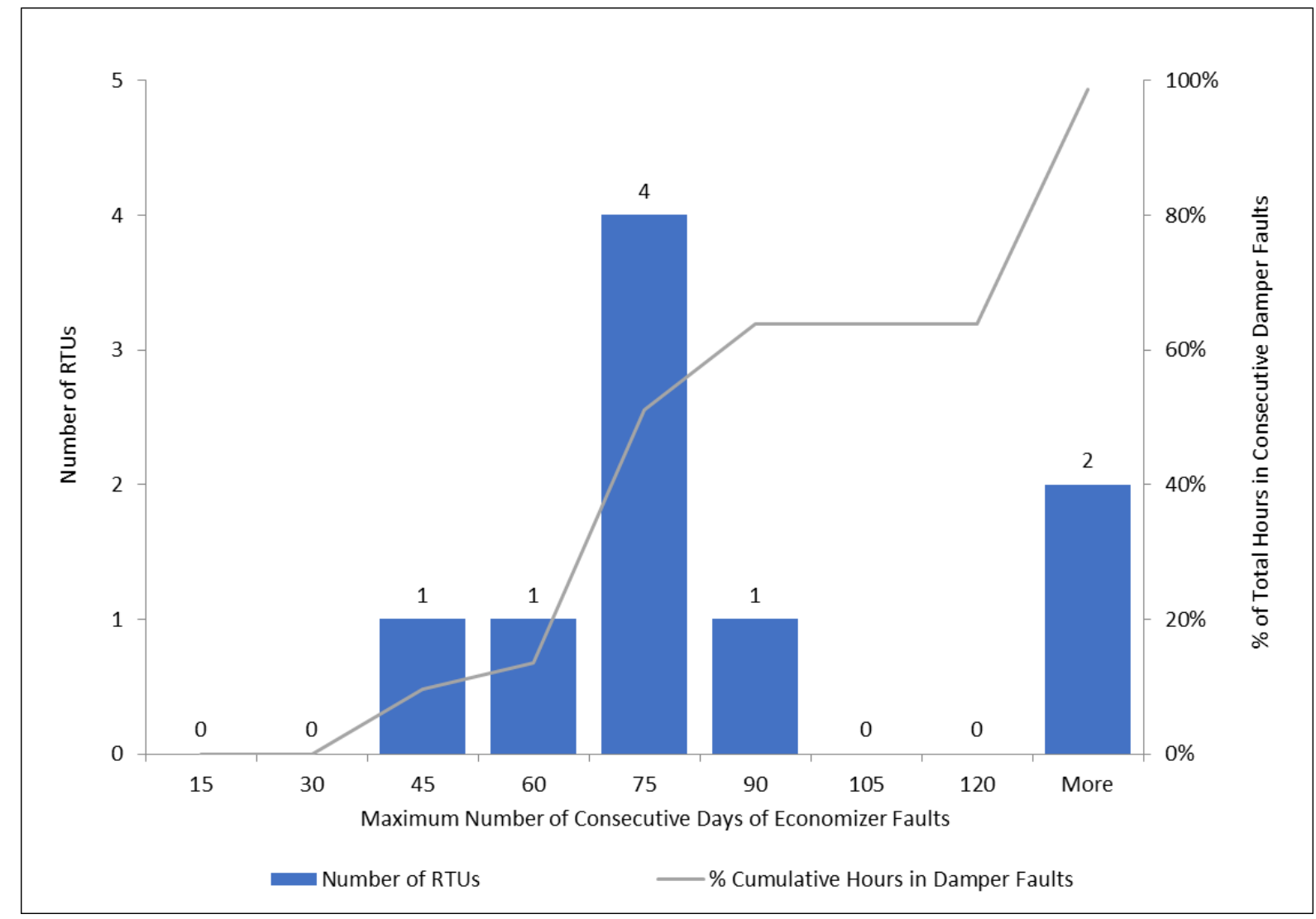

Figure 5. Consecutive days of reported economizer faults for the quick serve restaurant

\subsubsection{Analysis Company-A, Pharmacy}

The evaluation of the normalized AFDD faults from 133 RTUs was separated into two groups. The first group of 114 RTUs have economizers and the second group of 19 units do not. For the units with economizers, 98 have VFD controlled blowers and 16 do not. For the units that do not have economizers, 9 have VFD controlled blowers and 10 do not. The average hours of fault conditions based on 1,000 hours of operation can be seen in Figure 6. 


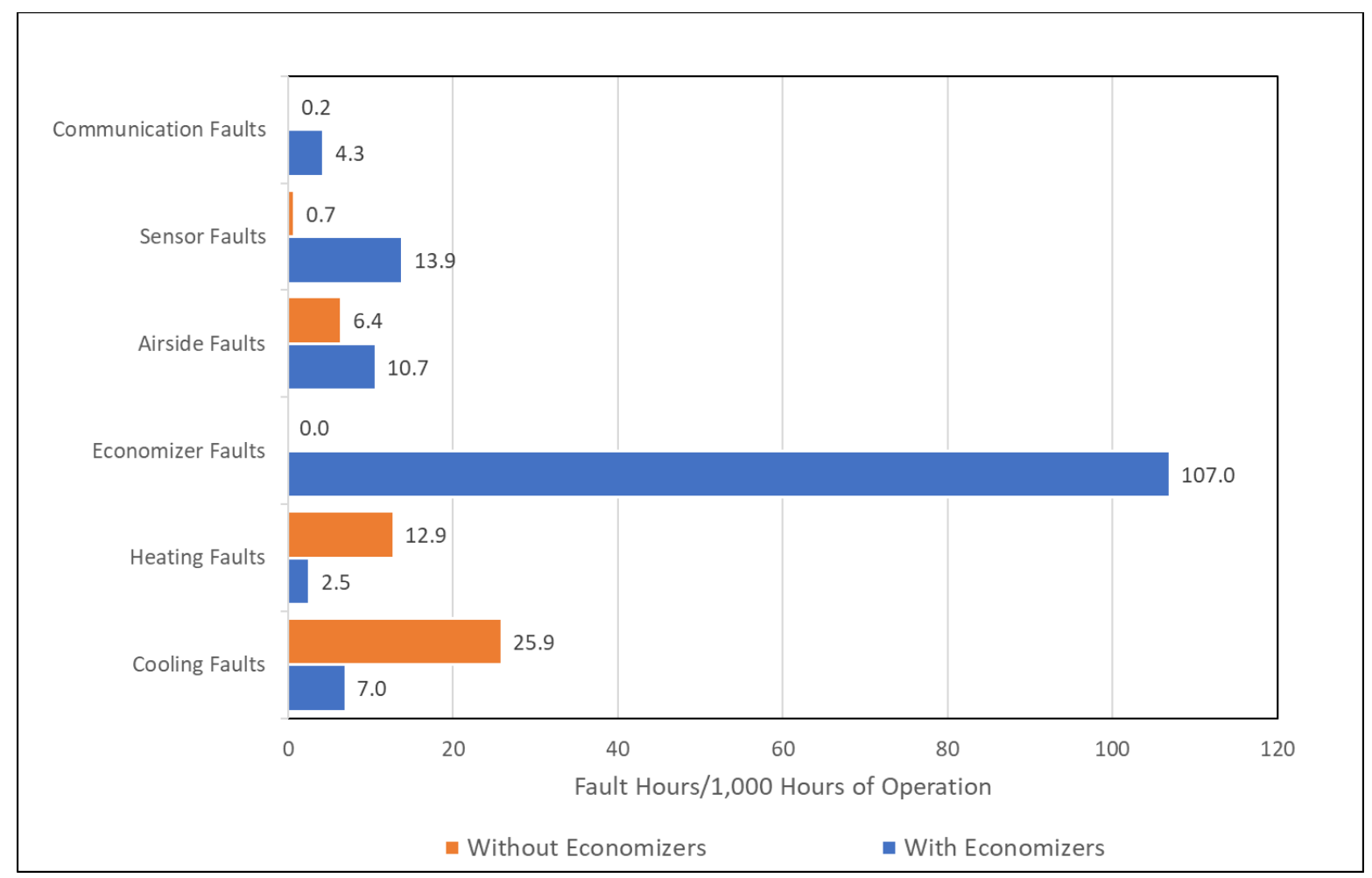

Figure 6. Fault hours per 1,000 hours of operation for rooftop units at the pharmacy sites

Comparing the two groups, units with economizers that generate damper faults are the most common issue. This data set does not have a more detailed breakdown with advanced economizer fault descriptions. In the absence of economizers, issues associated with heating, cooling, and airside system faults become more apparent. Units with fixed dampers versus modulating economizers are functionally simpler, and all but one RTU show periods of $80 \%-$ $100 \%$ fault-free operation as is seen in Figure 7. 


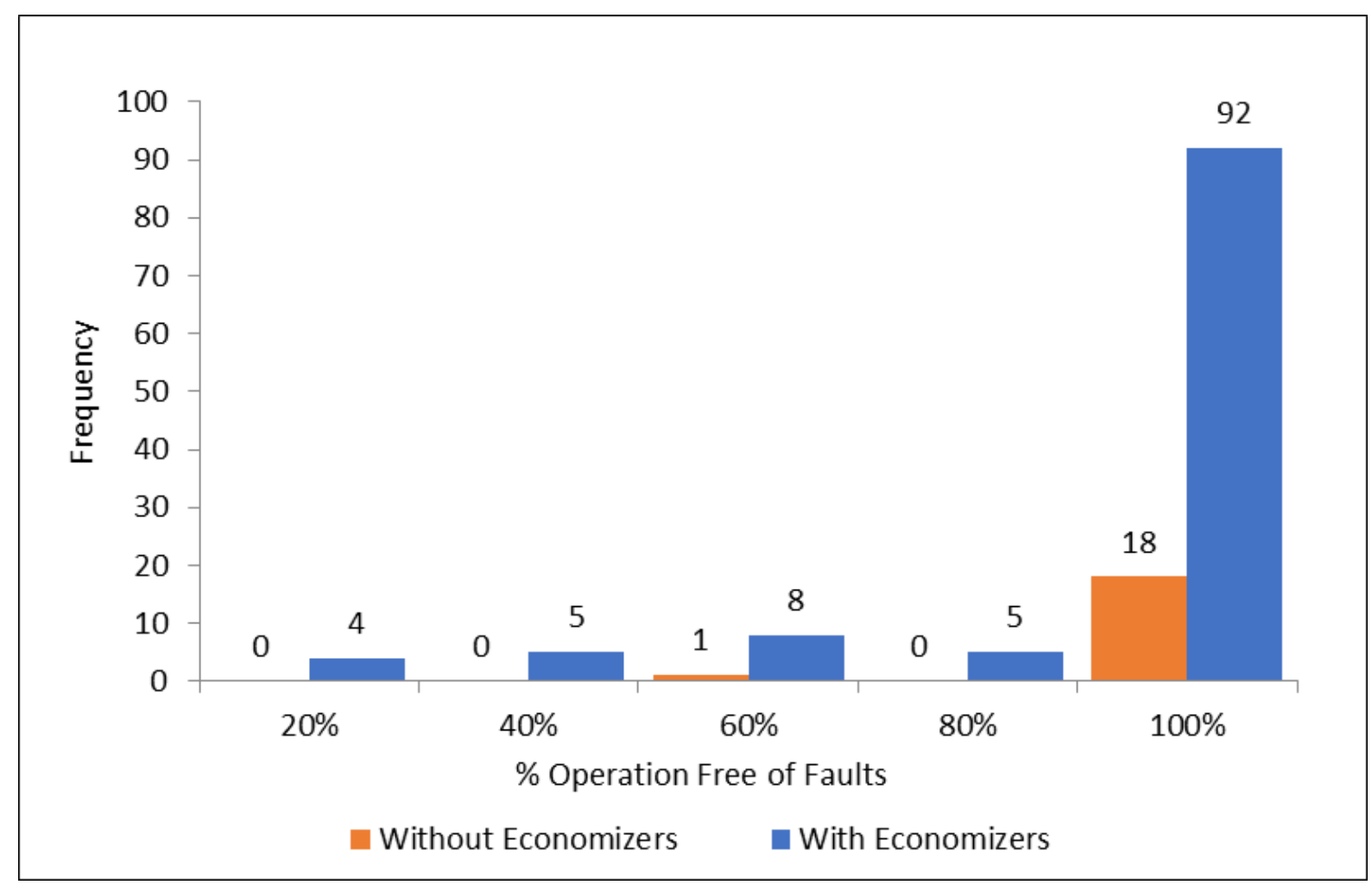

Figure 7. Percent of time rooftop units reported fault-free operation at the pharmacy sites

The RTUs with economizers again showed damper faults over many consecutive days without correction. Figure 8 shows the maximum number of consecutive days of uncorrected faults in the problematic RTUs, totaling more than $98 \%$ of the hours reported in damper faults. Thirty-seven of 114 units were problematic with consecutive days of damper faults. Of those 37, 10 account for more than $54 \%$ of the total hours of damper faults. Twelve of the 37 RTUs experienced 3 or more months of consecutive days with a fault. 


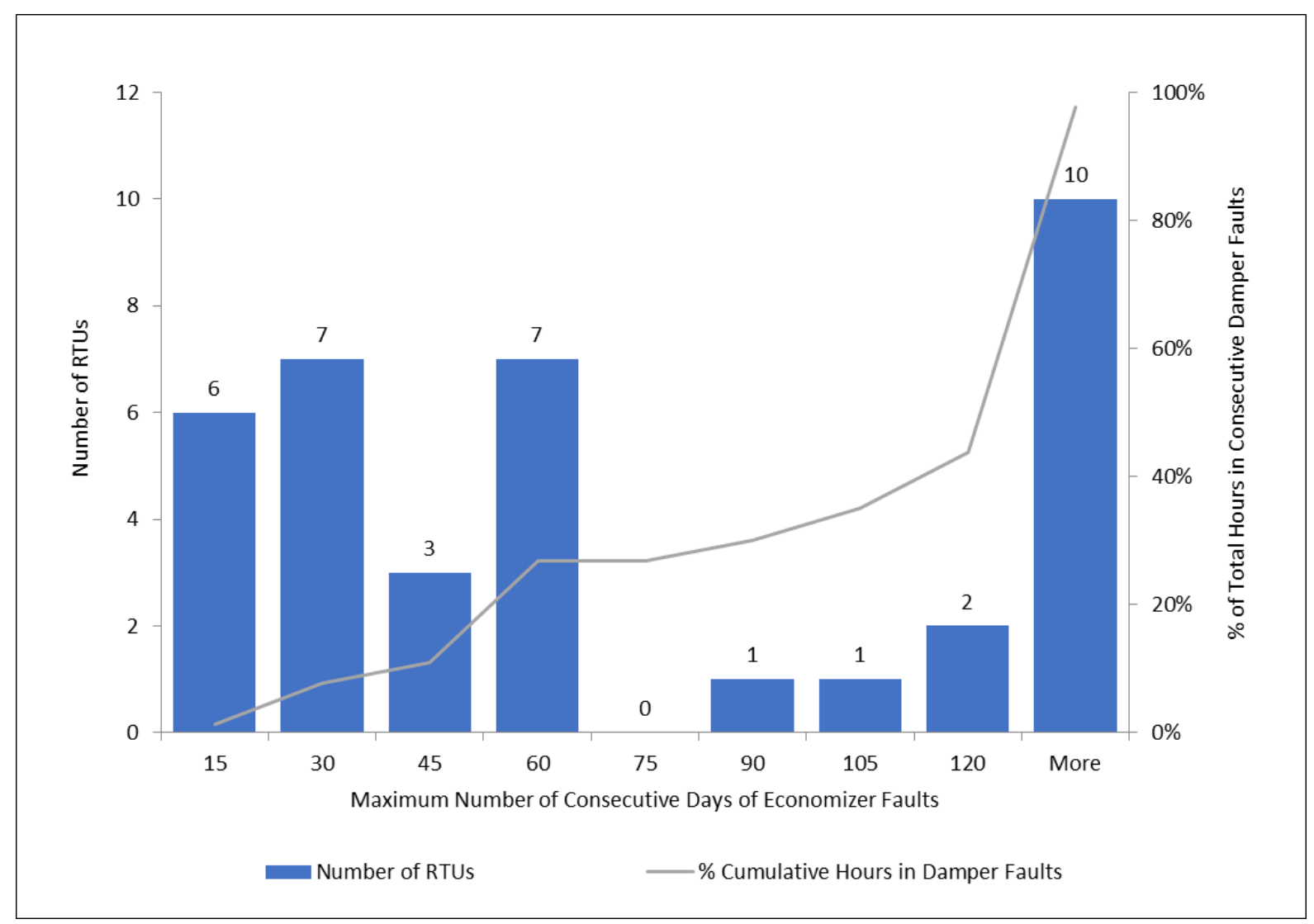

Figure 8. Consecutive days of reported economizer faults at the pharmacy sites

During the 37,392 RTU-days of daily summary reports from the 114 RTUs with economizers, there were 5,647 days when at least one fault was detected and 406 days when two or more faults were detected. On 4,210 days, there were damper faults related to the economizer. Furthermore, 399 days were reported to have an economizer fault as well as a heating or cooling fault.

Although the 399 days of heating or cooling faults accounts for only $2.5 \%$ of the total heating or cooling fault incidences, the erroneous operation of the economizer can create false positive diagnostics.

For the 19 RTUs without economizers, there were 6,232 RTU-days of daily summary reports during which 333 days contained least one AFDD fault and only 5 days when two or more faults were detected.

\subsubsection{Analysis Company-A, Clothing Retail Facilities}

The evaluation of the normalized AFDD errors from 1,689 RTUs was separated into two groups: 1,301 RTUs with economizers and 388 units without. Of the units with economizers, 1, 121 have VFD controlled blowers and 180 do not. Of the units without economizers, 244 have VFD controlled blowers and 144 do not. The average hours of fault conditions based on 1,000 hours of operation can be seen in Figure 9. 


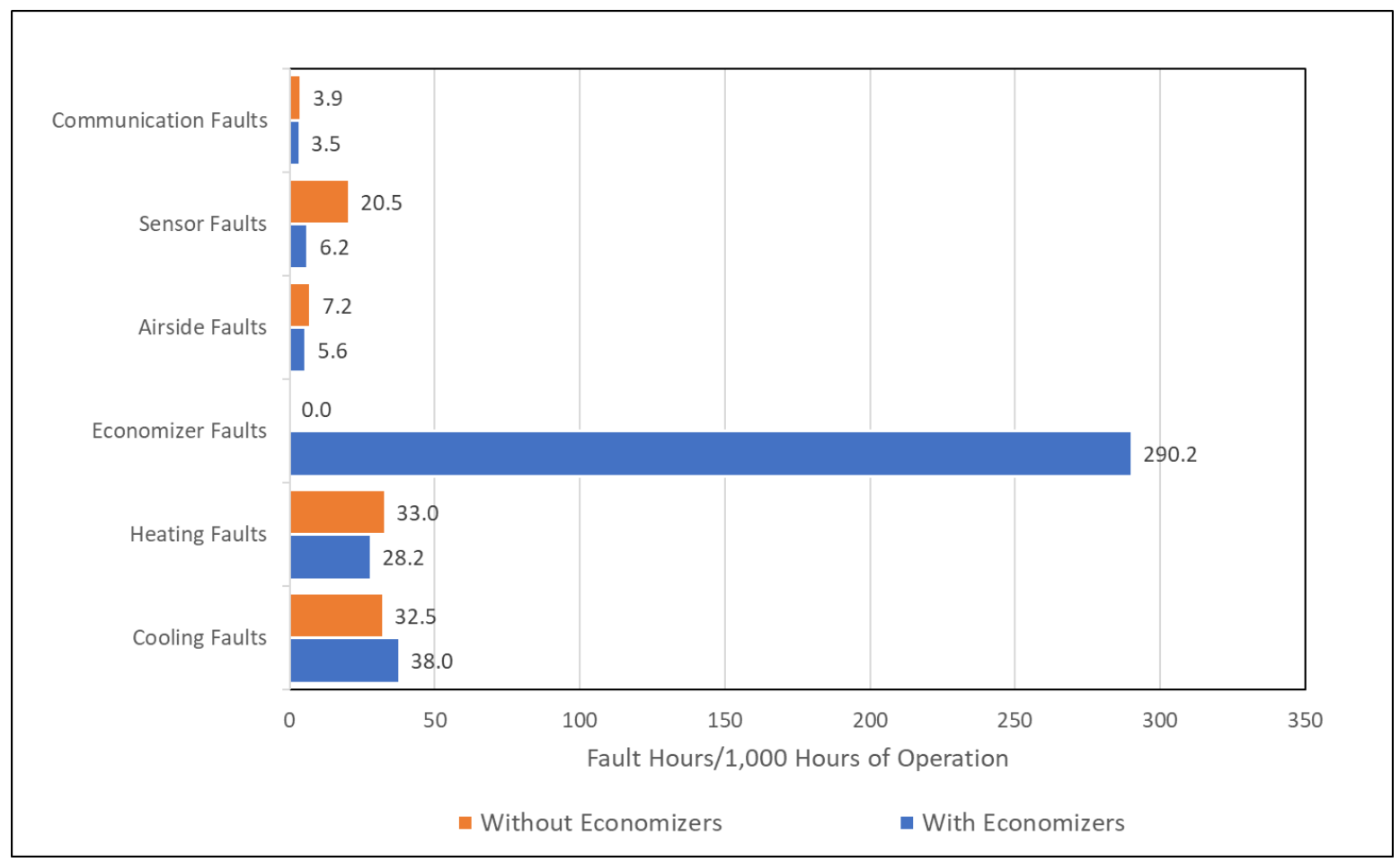

Figure 9. Fault hours per 1,000 hours of operation for rooftop units at the clothing retail sites

The 1,301 units with economizers had a normalized fault frequency of 290 hours per 1,000 operating hours or $29 \%$ of the time. For the 388 units without economizers, issues associated with heating, cooling, and sensor faults are the most prevalent, occurring $8.5 \%$ of the time during 1,000 hours of operation.

This data set has the advanced economizer fault information as shown in Figure 10. The percent distributions of the fault occurrences of the 1,301 RTUs with economizers is almost identical to the quick serve restaurant. The advanced economizer fault information may provide more insight into the damper issues if information related to the deviation from the expected set point was reported. 


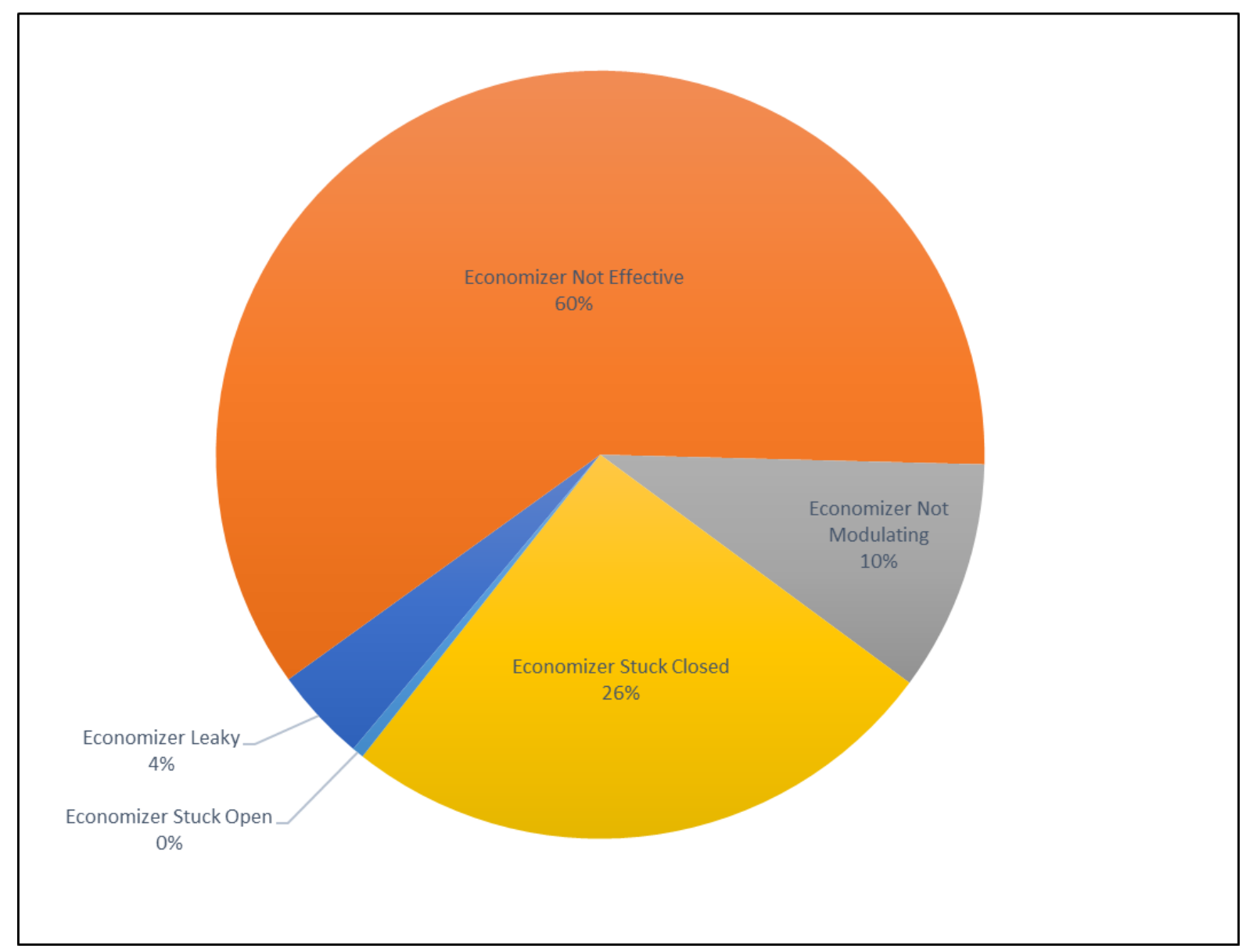

Figure 10. Clothing retailer advanced damper faults

Figure 11 and Figure 12 show the normalized frequency of faults per 1,000 hours of operation based on location, with and without economizers, respectively. Note that climate zone 1 (hot) and climate zone 7 (cold) have few RTUs and therefore the total number of RTU-hours prior to normalizing the data is significantly smaller. Although it makes sense that in hotter climates more cooling faults would be reported as seen in the RTUs with economizers, the units without economizers do not have consistent cooling fault frequency trends. Units without economizers appear to have more heating faults in colder climates, but this is less consistent with the units that have an economizer. 


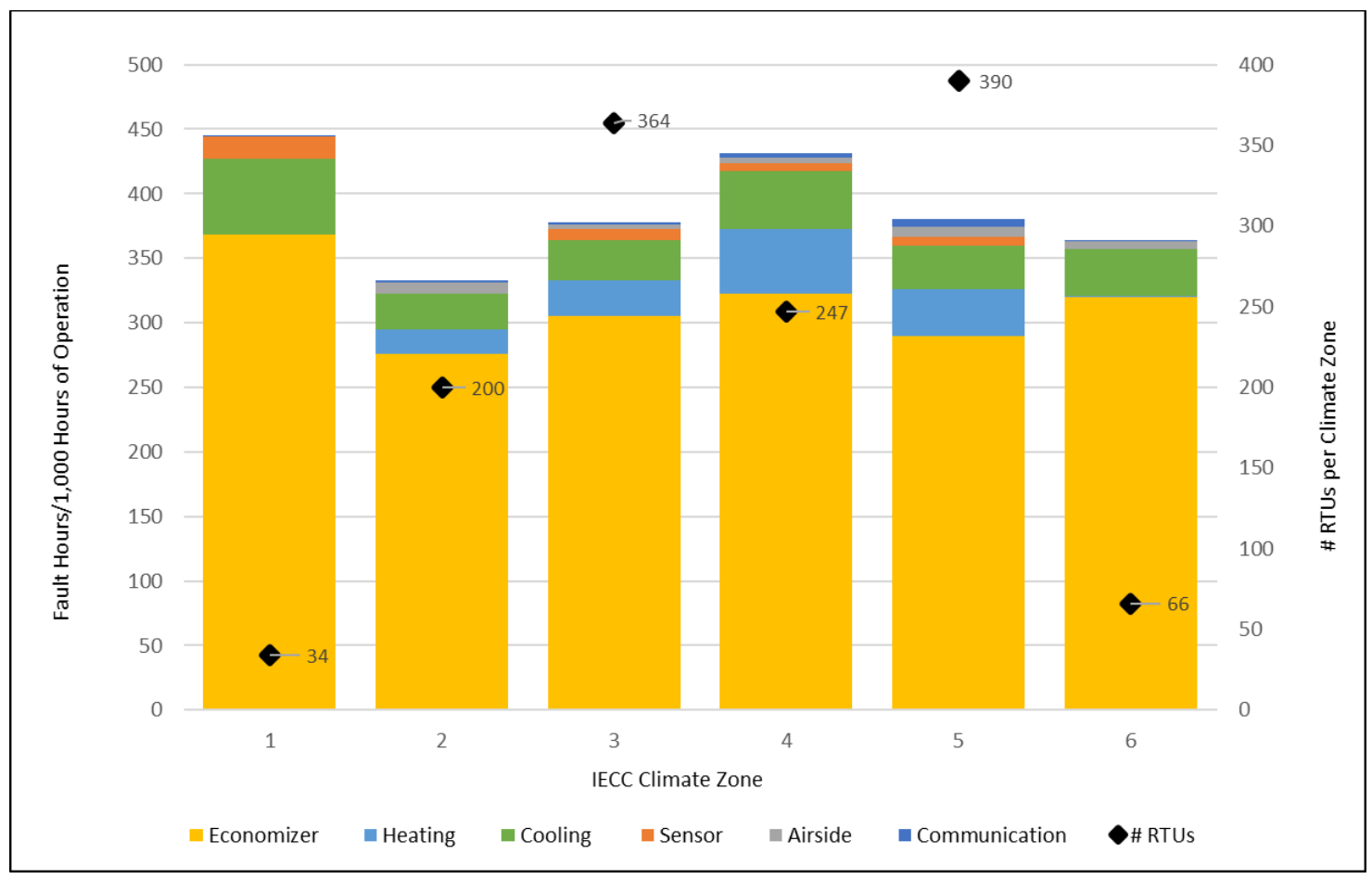

Figure 11. Fault hours per 1,000 hours of operation for rooftop units with economizers based on climate zone

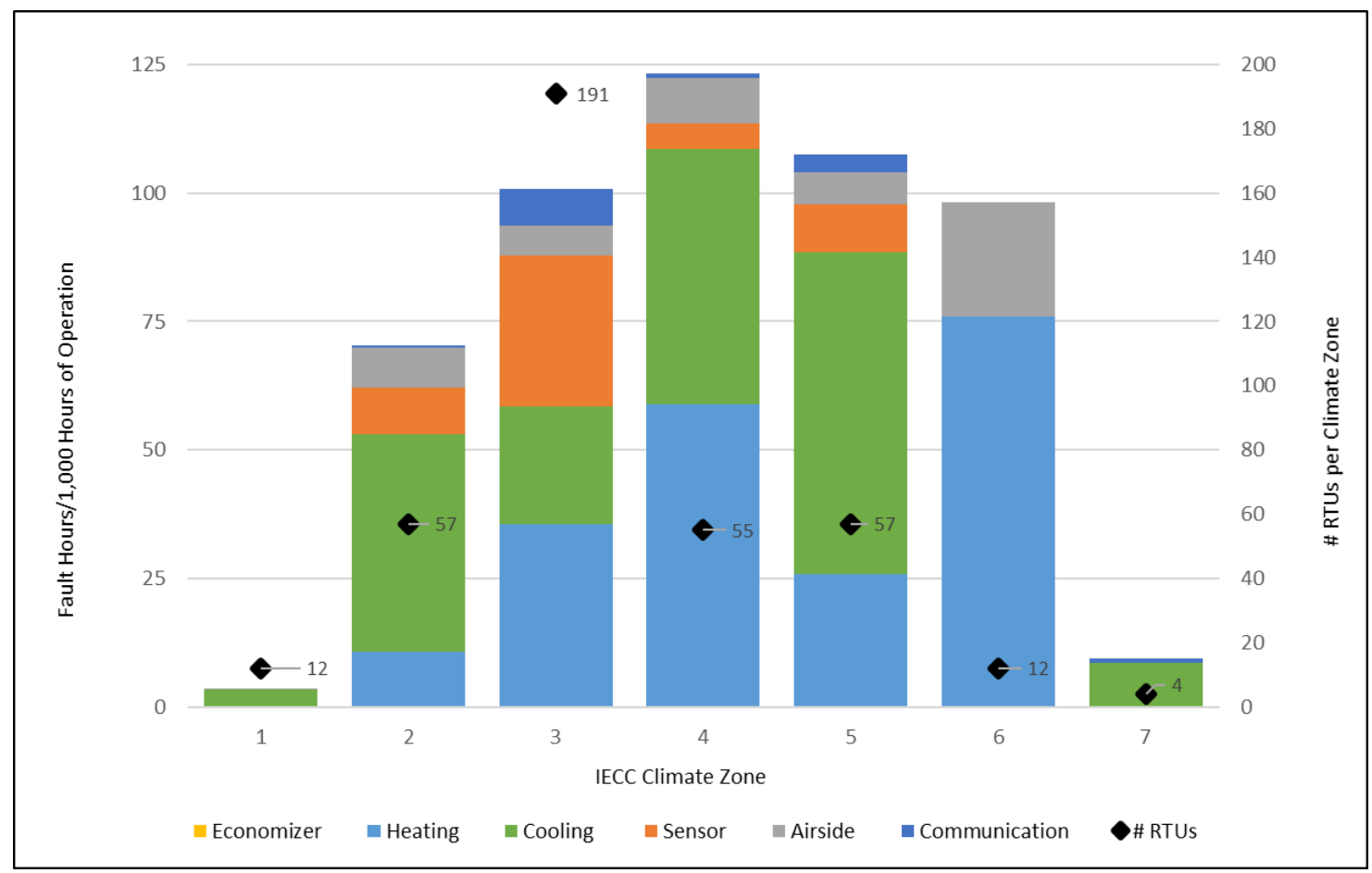

Figure 12. Fault hours per 1,000 hours of operation for rooftop units without economizers based on climate zone 
Figure 13 shows the number of RTUs at different levels of fault-free operation time. The distribution of RTUs shows $27 \%$ of units with economizers (or 356 RTUs) with most of the faults in this data set. Twenty-one of the RTUs (or less than 66\%) without economizers have significant operational anomalies: these units report $60 \%$ or fewer hours of fault-free operation. Thirty-five percent of the RTUs with economizers operate fault-free less than $60 \%$ of the time.

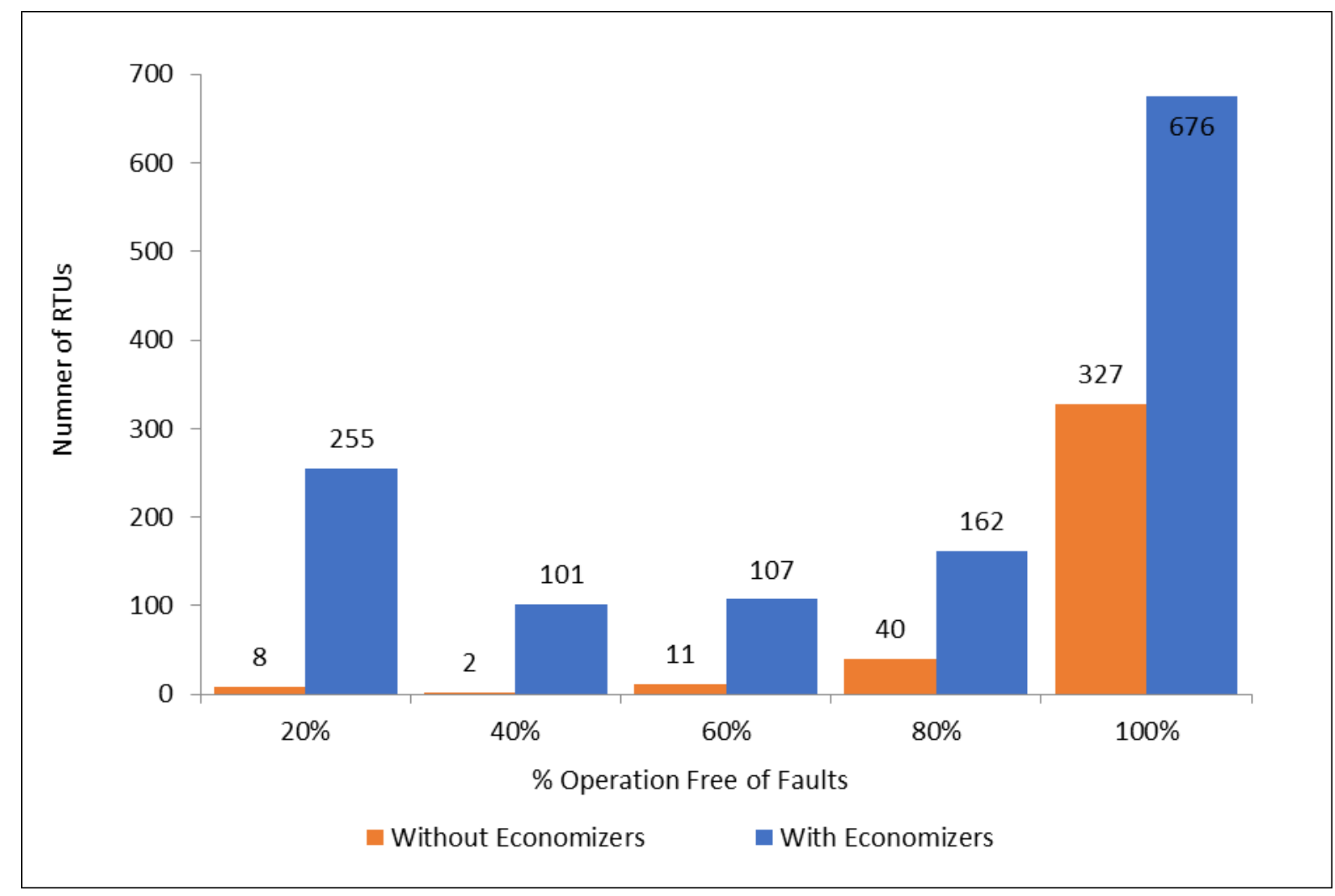

Figure 13. Percent of time rooftop units reported fault-free operation at the clothing retail store sites

Several RTUs within this data set report damper faults during many consecutive days. Figure 14 shows the maximum number of consecutive days of uncorrected faults in problematic RTUs, totaling $99 \%$ of the hours reported in damper faults. Of the 1,301 RTUs that have dampers, 305 units account for almost $70 \%$ of the damper faults, with more than 3 months of consecutive days in fault. 


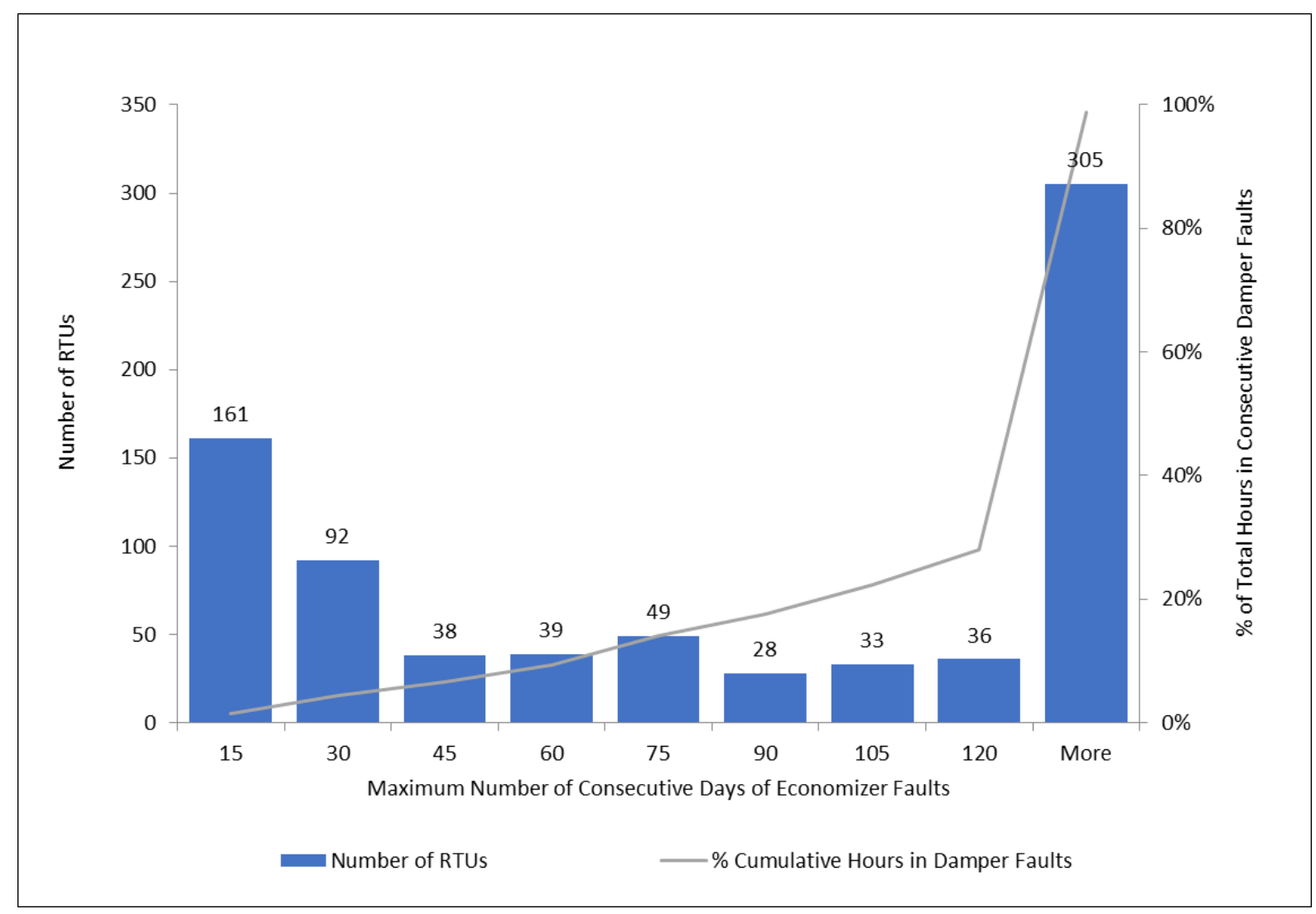

Figure 14. Consecutive days of reported economizer faults at the retail store sites

\subsection{Company-B, Faults and Definitions}

AFDD data for Company-B were provided by the building owner and did not include a comprehensive list of the faults and definitions that the system was capable of detecting. As faults are encountered by this system, a record is created. The faults reported in the data set are listed in Table 9. There may be other faults the BMS or equipment control boards are able to identify, but they were not reported during the time covered by the supplied data files. 
Table 9. Reported Building Management System and Rooftop Unit Control Board Faults by Company-B

\begin{tabular}{|c|c|}
\hline Fault Category & Fault \\
\hline \multirow{5}{*}{ Cooling } & Low Compressor Pressure \\
\hline & High Compressor Pressure \\
\hline & Compressor Lockout \\
\hline & Freeze Stat \\
\hline & Not Meeting Set Point \\
\hline \multirow{4}{*}{ Heating } & High Heating Limit \\
\hline & No Proof of Gas Valve Flow \\
\hline & Combustion Air Switch \\
\hline & Not Meeting Set Point \\
\hline \multirow{6}{*}{ Sensor } & Air Quality $/ \mathrm{CO}_{2}$ Sensor \\
\hline & Outdoor Temperature \\
\hline & Indoor/Outdoor Humidity \\
\hline & Supply Air Temperature \\
\hline & Return Air Temperature \\
\hline & Zone Temperature \\
\hline \multirow{2}{*}{ Communication } & Modbus \\
\hline & BACnet \\
\hline Power/Phase & Power/Phase Loss \\
\hline Airside & Blower Lockout \\
\hline \multirow{4}{*}{ Other } & Lighting Sensors \\
\hline & Smoke Alarms \\
\hline & Control Boards \\
\hline & Domestic Hot Water Set Point \\
\hline
\end{tabular}

\subsubsection{Analysis Company-B, Small-Box Retail Store}

The data set from AFDD Company-B contains 13 months of data with 1,400 recorded faults from 371 sites. Figure 15 shows the binned number of faults versus the number of sites. The few sites that report 20 or more significant fault records have persistent problems related to loss of communication or out of range sensor readings relative to a set point. 


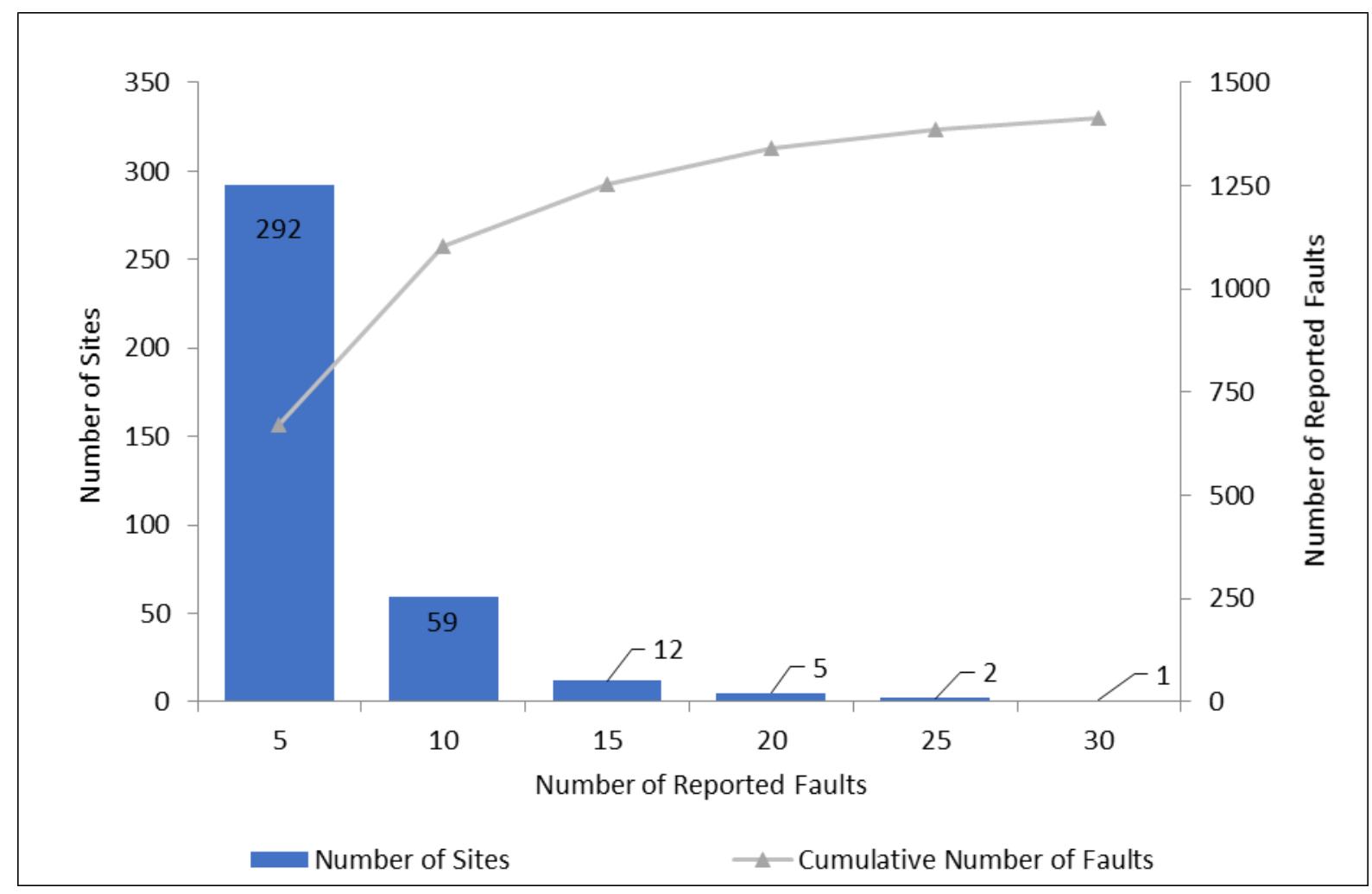

Figure 15. Frequency of the number faults at 371 sites reported by Company-B

Most of the faults are classified as sensor and communication faults as shown in Figure 16. Sensor faults are triggered if a measured value is outside the set point or expected range. Both the measured value and the set point value are reported. Only a few of the temperature sensor fault records are completely erroneous, reading either excessively large values, excessively small values, or negative values. Most of the temperature sensor faults deviate slightly from the set point and are not sensor faults. Most of the faults associated with humidity measurement appear erroneous with negative values reported. Out of range faults could be an indicator of a performance issue related to the equipment's failure to provide adequate space conditioning. The faults that show excessively large values, excessively small values, or negative values may be an indication of a broken sensor or bad wiring. 


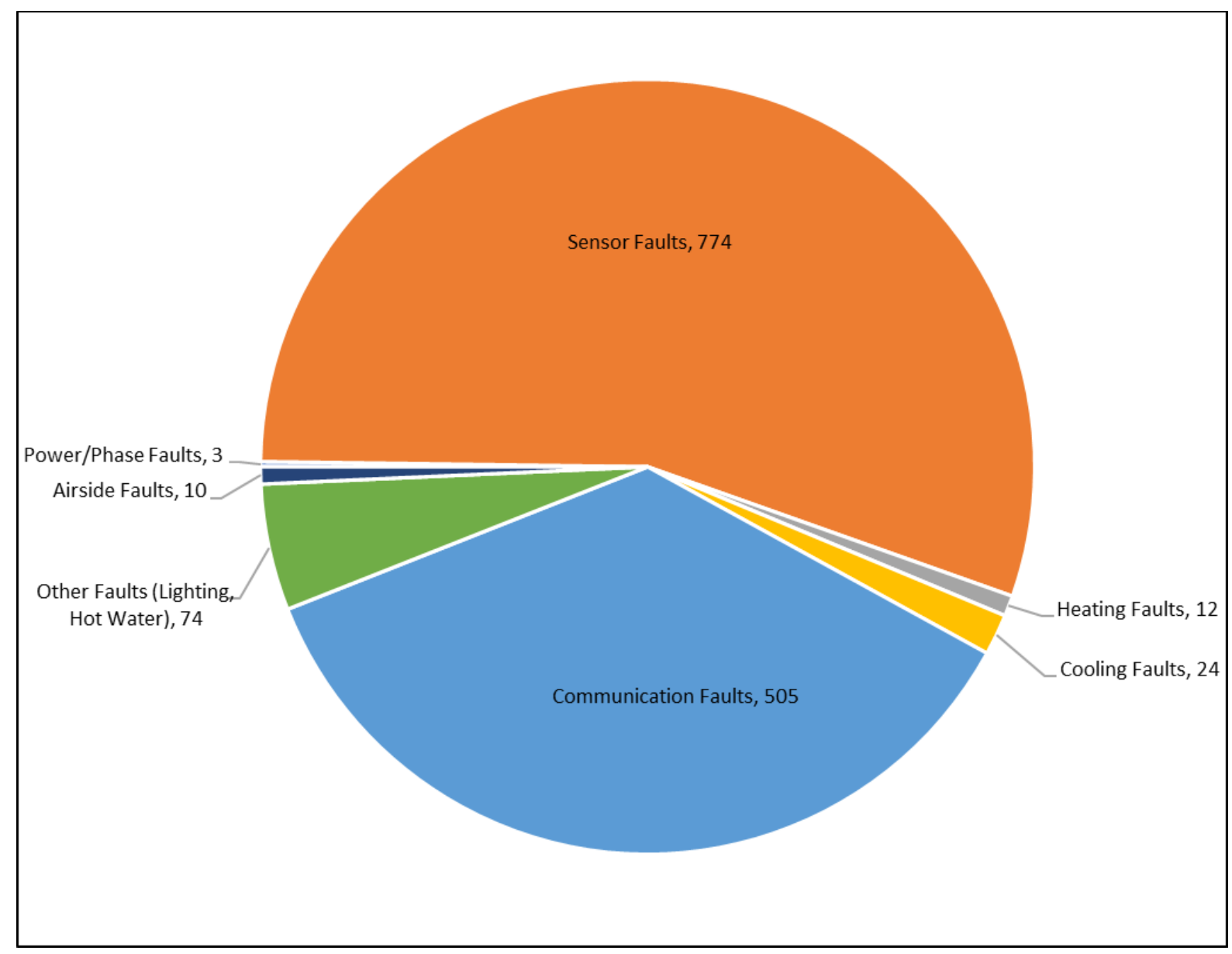

Figure 16. Fault frequency for rooftop units at small-box retail stores

\subsection{Company-C, Faults and Definitions}

AFDD data from Company-C were also provided by the building owner and did not include a comprehensive list of faults and definitions their system is capable of detecting. Records are created as faults are encountered by this system. Table 10 lists the faults reported in the data set. The complete list of faults that the system is capable of detecting is unknown and may include other faults besides the faults listed in Table 10 . 
Table 10. Reported Building Management System and Rooftop Unit Control Board Faults by Company-C

\begin{tabular}{|c|c|}
\hline Fault Category & Fault \\
\hline \multirow{5}{*}{ Cooling } & Low Compressor Pressure \\
\hline & High Compressor Pressure \\
\hline & Compressor Lockout \\
\hline & Freeze Stat \\
\hline & Not Meeting Set Point \\
\hline \multirow{4}{*}{ Heating } & High Heating Limit \\
\hline & No Proof of Gas Valve Flow \\
\hline & Combustion Air Switch \\
\hline & Not Meeting Set Point \\
\hline \multirow{6}{*}{ Sensor } & Air Quality/CO 2 \\
\hline & Outdoor Air Enthalpy \\
\hline & Outdoor Air Temperature \\
\hline & Supply Air Temperature \\
\hline & Return Air Temperature \\
\hline & Zone Temperature \\
\hline \multirow{3}{*}{ Communication } & Modbus \\
\hline & BACnet \\
\hline & $\mathrm{XCM}$ \\
\hline \multirow{2}{*}{ Power/Phase } & Power/Phase Loss \\
\hline & Demand Usage Warning 5 \\
\hline \multirow{3}{*}{ Other } & Lighting On/Off Override \\
\hline & Lighting Sensors \\
\hline & Security System \\
\hline
\end{tabular}

\subsubsection{Analysis Company-C, Small-Box Retail Store}

The data set from AFDD Company-C displays one week of data. During this short period of time, 575 faults were reported at 123 sites. The top 20 sites represent $50 \%$ of the total faults, mostly related to the sensor readings. Figure 17 shows the number of reported faults at the 123 sites.

\footnotetext{
${ }^{5}$ This fault was reported when the demand usage was $30 \%$ higher than the previous day.
} 


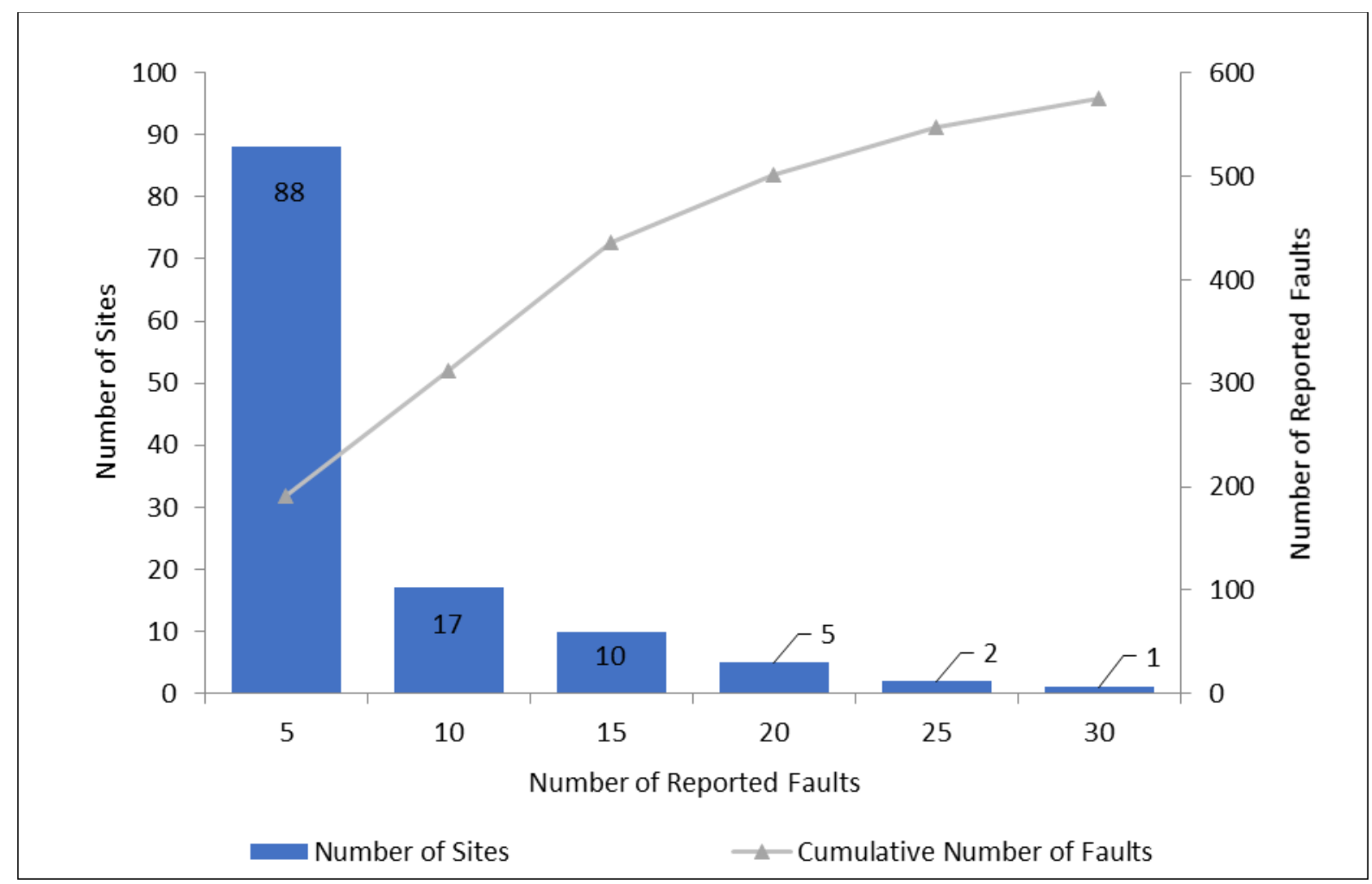

Figure 17. Frequency of faults at 123 sites reported by Company-C

Most of the faults are related to sensors and indicate a measured value outside a set point or expected range. This could be related to an issue of the heating, cooling, or ventilation system. Only a few of these sensor fault records are completely erroneous, which may indicate a broken sensor or bad wiring. Although the sensor value is reported with respect to each record, the set point is not. Reporting the set point value is equally useful to understand whether the measured value is slightly or significantly out of range.

Of the 139 faults related to the power/demand/phase fault category, 132 are demand usage warnings. ${ }^{5}$ Only seven times was there a power issue related to loss of a phase or a blackout. 


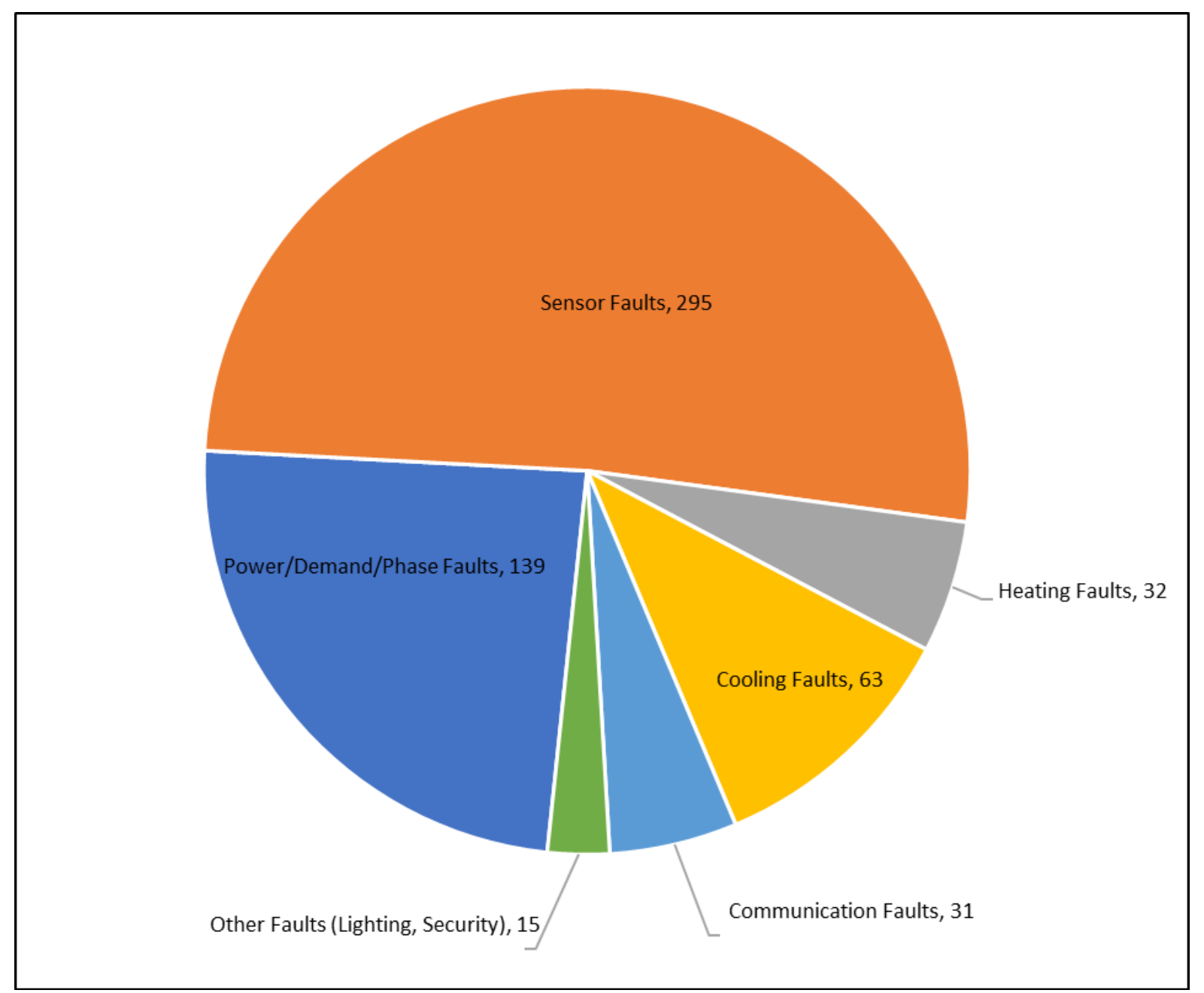

Figure 18. Fault frequency for rooftop units at small-box retail stores

In Figure 18, the RTU control board provided 79 of the 575 AFDD faults where 25 faults pertained to sensors, 22 faults were related to heating issues, and 32 faults were related to cooling issues. AFDD systems that can identify faults from the RTU control board can assess specific faults associated with hardware that other systems might not. These boards can identify issues with low or high refrigerant pressure; fouled coils and filters; and faulty dampers, pressure switches, ignitors, and gas valves.

This data set also includes notes stating that work orders were created to service the faulty units based on AFDD data. Due to duplicate work order numbers reported for different faults at multiple sites, this information could not be used in the analysis. However, keeping accurate records of corrective actions along with accurate fault information can provide data that may support less frequent faults and cost savings over time.

Like Company-B, this data set showed mostly sensor faults. Although the data sets had different reporting structures and slight differences in the characterization of faults, there were a lot of similarities due to monitoring a common building portfolio client. The most notable of the similarities is the frequency of sensor faults due primarily to out of range values. These systems 
had identical monitoring architectures that communicate with the BMS as well as some of the RTU control boards. The building site operations staff had the ability within this system to document work orders and notes regarding service calls, although this capability was rarely executed.

When out of range values were identified by the AFDD system, Company-B included additional information about the set point values while Company-C did not, despite both monitoring RTUs for the same customer. Both companies' data sets required a significant amount of raw data cleanup due to replicate entries, missing data, and inconsistent records. The structures of the data sets were different enough to make a simple analysis and comparison of faults across the smallbox retail stores difficult. Standardization of the data structure and reporting would make a more accurate comparison possible.

\subsection{Company-D, Faults and Definitions}

Company-D provided a summarized table of their fault categories and the frequency of the occurrences. The five categories for which Company-D reports its predictive fault indicators are characterized as cooling, heating, economizer/damper, sensors, or communication anomalies. Although airside issues are not an explicit category, these detected issues can fall into either the heating or cooling categories depending on the mode of operation the RTU was in during the detected fault. This was the only data set that included information on the age of the equipment.

\subsubsection{Analysis Company-D, Big-Box Retail Stores}

The figures below show the fault categories and frequency of Company-D's AFDD cloud-based system, which uses the existing BMS and installed building sensors. The figures reflect 25,800 RTUs that condition big-box retail stores located in 1,733 locations. Of these RTUs, it is unknown how many have economizers, whether the blowers have VFDs, or what types of heating systems are included. The distribution of fault frequency can be seen in Figure 19. Cooling anomaly is the most frequently reported fault followed by communication issues. Unlike the fault frequency data provided by Company-A, these data show the least number of faults are due to the economizing damper. 


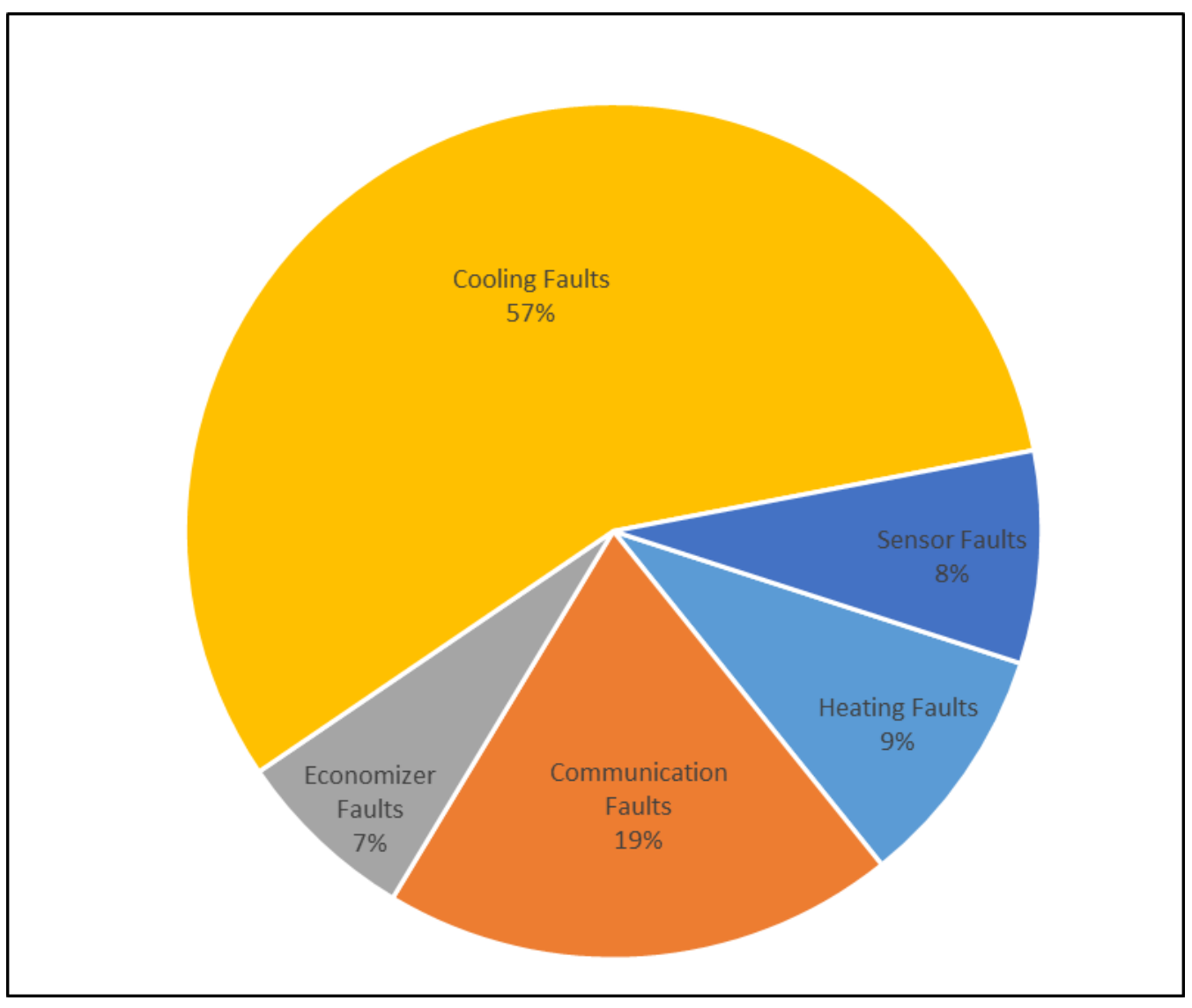

Figure 19. Fault frequency by percent for rooftop units at the big-box retail stores

Figure 20 the shows the percentage of faults per climate zone. We see that the smallest number of RTUs, located in the hot and humid climate zones, showed the greatest number of faults. In addition, Company-D provided information on the age of the RTUs and the climates in which they are located. This can be seen in Figure 21. Despite the greatest number of faults occurring from RTUs in the hot and humid climate zone, $84 \%$ of those units are less than 10 years old. In addition, we see that RTUs in moderate and cold climates primarily make up RTUs that are 10 years of age or older. 


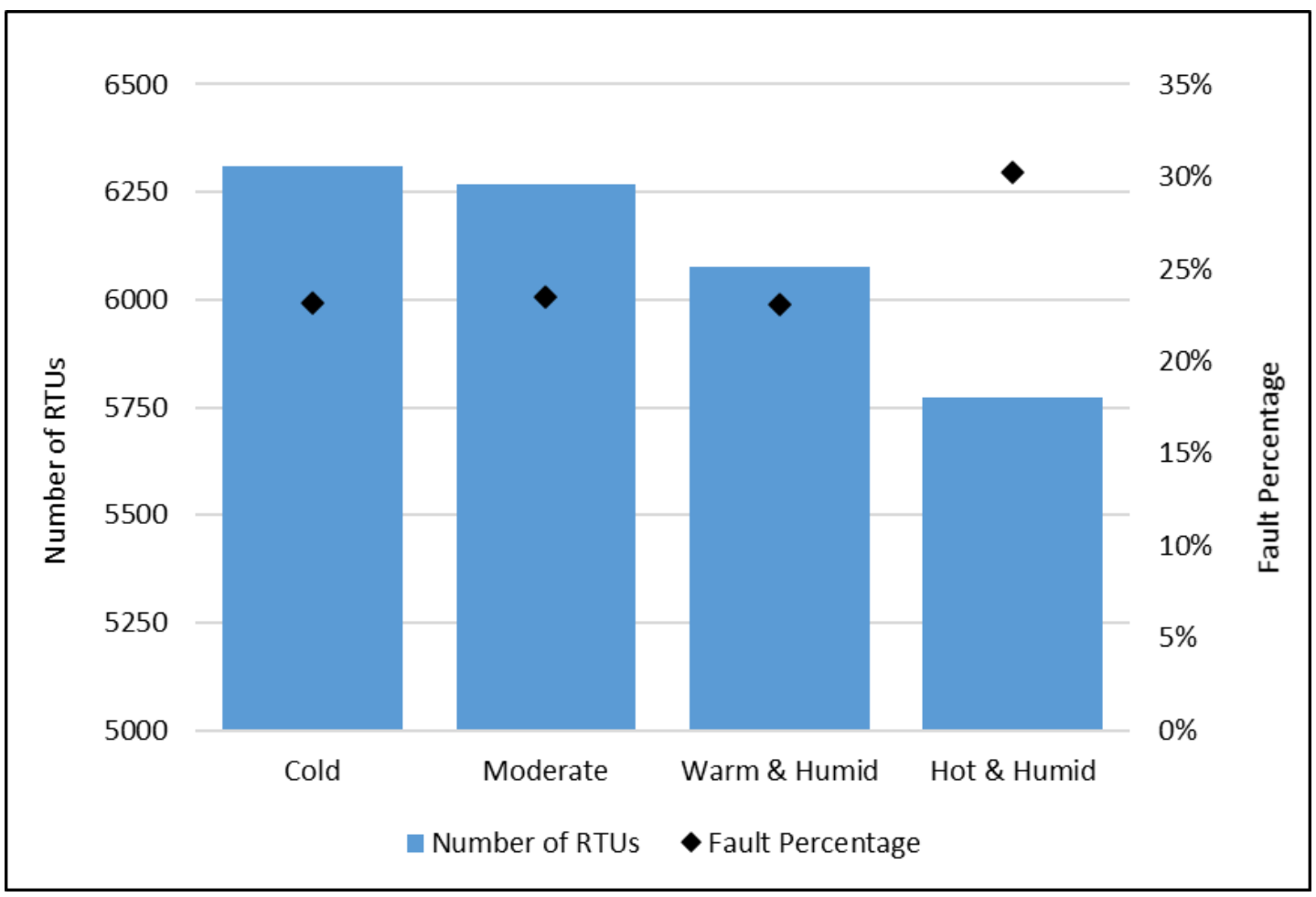

Figure 20. Number of rooftop units and the percentage of faults detected from the RTUs in each of the climate zones

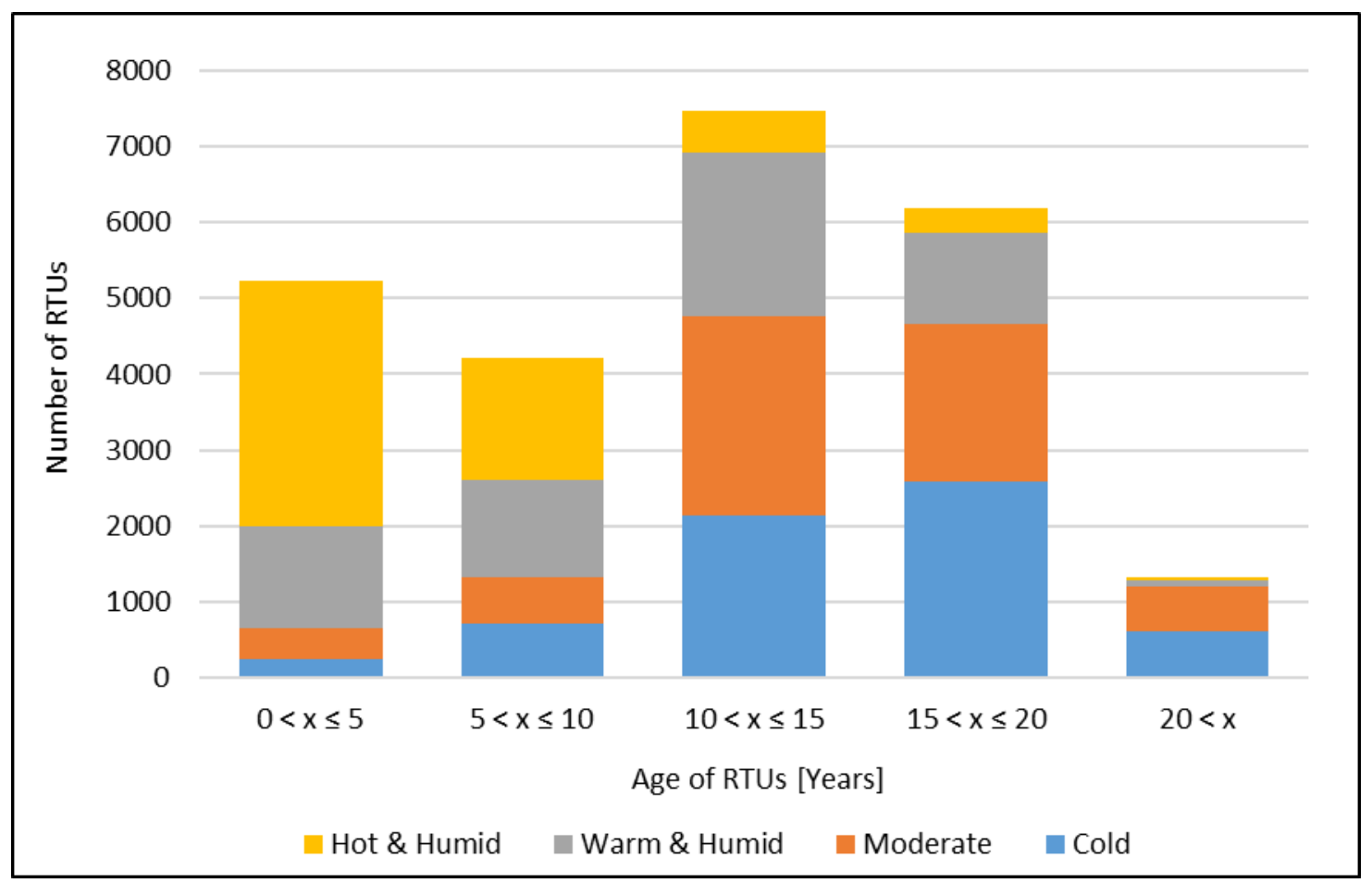

Figure 21. Number of rooftop units in four climate zones binned by age 
Company-D reported that during 6 years of AFDD algorithm refinement using their historical data, they have demonstrated that their system has shifted to predictive fault diagnostics. In 2015 , Company-D had $85 \%$ reactive versus $15 \%$ predictive fault detection. Then, in 2019 , their system demonstrated $40 \%$ reactive and $60 \%$ predictive diagnoses. This was verified by documenting the faults reported and comparing them to the services performed to correct the anomalies.

They also reported that during the last 2-year period, they have shown a 93\% success rate for predictive detection identifying RTU behavioral issues, which were fixed either remotely through the cloud-dashboard or through a service call to a technician. Of the fixes documented, $66 \%$ of them pertain to failed parts, equipment resets, or faulty wiring. Figure 22 shows the 30 most frequently replaced parts on an average annual basis identified by the AFDD system and during regular preventative maintenance visits.

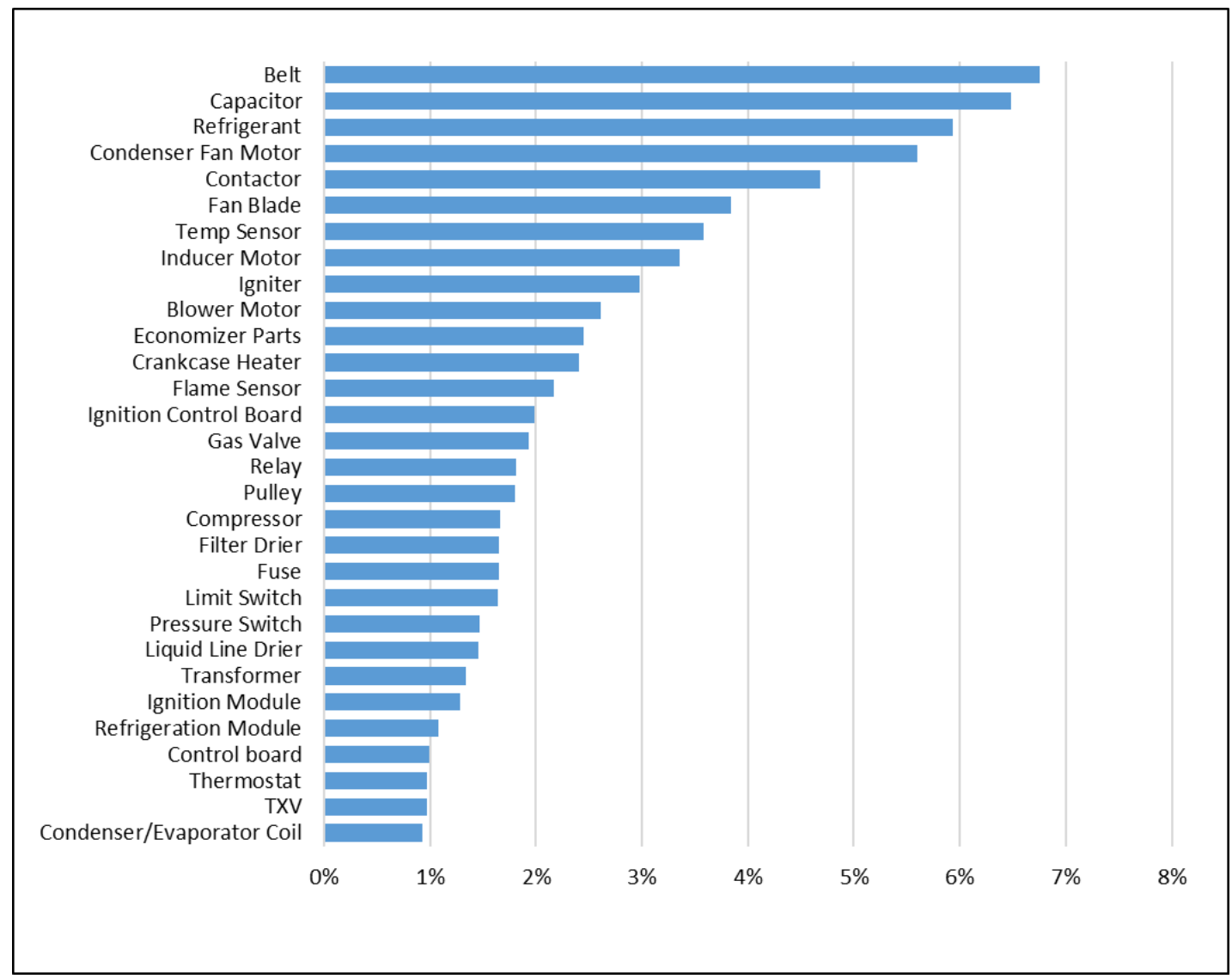

Figure 22. The 30 most common parts replaced by Company-D

By moving to a predictive FDD system, Company-D demonstrated ways to save money in addition to ensuring the equipment is running at optimal efficiency. Because only some of the behavioral issues require on-site repairs, $80 \%$ of the faults can be addressed remotely. This has reduced work orders by $30 \%$ and technician visits by more than $20 \%$. When a service call to a technician is required, work associated with proactive maintenance can be bundled and performed during the same visit. This reduces the number of technician visits by shifting scheduled maintenance items to a proactive approach because the behavioral anomalies in a system have already been identified. 


\section{Conclusions and Recommendations}

In a previous AFDD study, Wheeler et al. (2020) interviewed AFDD providers and building owners to better understand what AFDD systems are available and what features are beneficial to building owners. The present report analyzes data reported from AFDD systems on more than 28,000 RTUs to determine frequency of reported faults, how AFDD systems operate, and how operators interact with the AFDD systems.

Working with these data sets has revealed a variety of AFDD applications, system integrations, fault definitions, and communication approaches. Some of the variations are necessary and beneficial to best support the building owner; however, many of the differences require expensive customizations and may lead to missed faults and misdiagnosis of faults. In addition, differences in fault definitions and reporting make direct comparisons between AFDD systems challenging and limited conclusions can be drawn from such comparisons. Different frameworks and fault definitions can lead to the same fault being classified in different categories and lead to different and inappropriate corrective actions. These potential conflicts support a need for well accepted fault definitions as well as a more unified understanding how faults should be characterized to provide consistency across AFDD companies (Frank et al. 2019).

Integration of AFDD systems with the building and owner management systems is important to performance and usability. Effective AFDD systems should be agnostic and integrate easily with multiple RTU brands and building automation system types. In addition, AFDD reporting should integrate with building asset maintenance and management systems for the most efficient operations. The methods and content of fault communications are critical to effective follow-up actions. Communications of faults should include fault details, critical data to understand the severity of the faults, and other actionable information. Tracking and trending of RTU performance, reported faults, and required maintenance is very beneficial and cost-effective for robust RTU (and other systems) maintenance and management programs.

From the data analyzed we can draw a few conclusions:

1. The types and frequency of reported faults depends on the fault definitions and the diagnostic approaches. The diversity of points monitored, the definition of faults, and the structure of the reporting makes comparison between AFDD companies difficult. Four different companies reported the most prevalent faults from four different fault categories related to economizer dampers, sensors, communications, and cooling systems.

2. Faults reported within a specific category may have resulted from anomalies associated with another component. For example, an undetected damper stuck open, could result in a cooling system fault due to the RTU not being able to meet the cooling set point.

3. AFDD systems that can communicate with the RTU control board can identify specific anomalies associated with hardware such as failed pressure switches, ignitors, gas valves, or fouled coils and filters. This provides a level of diagnostics to characterize a fault more accurately.

4. RTU faults are often associated with a small number of problematic RTUs, which may benefit from dedicated maintenance efforts. Regular preventative maintenance on well 
performing RTUs may be reduced based on the results of continuous monitoring from the AFDD systems.

5. Closed loop AFDD systems that include monitoring RTU performance, space conditions, and weather conditions; building operations; and maintenance can provide long-term cost-effective performance. Continuous improvement through learning cycles is important to improving performance.

Based on the information available and the attempt to sort and analyze the data, recommendations for improving the effectiveness of AFDD systems include:

1. When an AFDD system reports a fault associated with quantitative values, report the out of range value and the desired set point associated with the fault.

2. Report faults as they are detected to include information that is concise, consistent, and structured into a few basic, well-defined categories. This provides an easy to understand message regarding the problem.

3. Associate an economic impact with the detected faults to help building owners understand the cost implication and importance of repairing their equipment.

4. Keep a historical database of organized and structured AFDD data so that retroactive analyses can be performed to provide better fault diagnosis and more robust rule-based detection.

5. AFDD systems should be linked to HVAC asset and maintenance databases to streamline trouble shooting, repair, and replacement efforts. Problematic units, based on equipment age and service frequency, can then be identified as the best candidates for replacement.

6. Records of work orders and repairs should be maintained and coordinated with the AFDD data set so that the frequency of service and maintenance is documented. This can help provide data needed to evaluate energy savings, operational and maintenance cost savings, and the return on investment of an AFDD system.

7. Identify faults that can be fixed by on-site staff or remotely through modifications in controls, set points, or resets. Other lower priority faults can be bundled into scheduled maintenance work orders to save costs by minimizing the number of technician site visits. 


\section{References}

ASHRAE. 2013. Standard 169-2013. Climatic Data for Building Design Standards. Atlanta, GA: ASHRAE.

EIA (U.S. Energy Information Administration). 2012. Commercial Building Energy

Consumption Survey. Consumptions and Expenditures, Table E5, May 2016. Washington, DC:

Energy Information Administration. https://www.eia.gov/consumption/commercial/.

EIA (U.S. Energy Information Administration). 2019. Frequently Asked Questions (FAQS).

Washington, DC: Energy Information Administration.

https://www.eia.gov/tools/faqs/faq.php?id=86\&t=1.

Frank, Stephen, Guanjing Lin, Xin Jin, Rupam Singla, Amanda Farthing, and Jessica Granderson. 2019. "A performance evaluation framework for building fault detection and diagnosis algorithms," Energy and Buildings, 192: 84-92.

Heinemeier, K. 2012. Rooftop HVAC Fault Detection and Diagnostics: Technology and Market Review Energy and Demand Savings Estimates. CEC PIER. Sacramento, CA: California Energy Commission.

Katipamula, Srinivas, and Michael R. Brambley. 2005. "Methods for Fault Detection, Diagnostics, and Prognostics for Building Systems-A Review, Part I." HVAC\&R Research, 11, no. 1. DOI: 10.1080/10789669.2005.10391123.

Wheeler, Grant, Michael Deru, Adam Hirsch, and Kim Trenbath. 2020. Provider and User Perspectives on Automated Fault Detection and Diagnostic Products for Packaged Rooftop Units, NREP/TP-5500-75461. https://www.nrel.gov/docs/fy20osti/75461.pdf. 


\section{Appendix A. Additional Data}

In this appendix we included the data that were provided to NREL that is not directly related to the analysis that we performed.

Figure A-1 shows the IECC climate zone map for the continental United States.

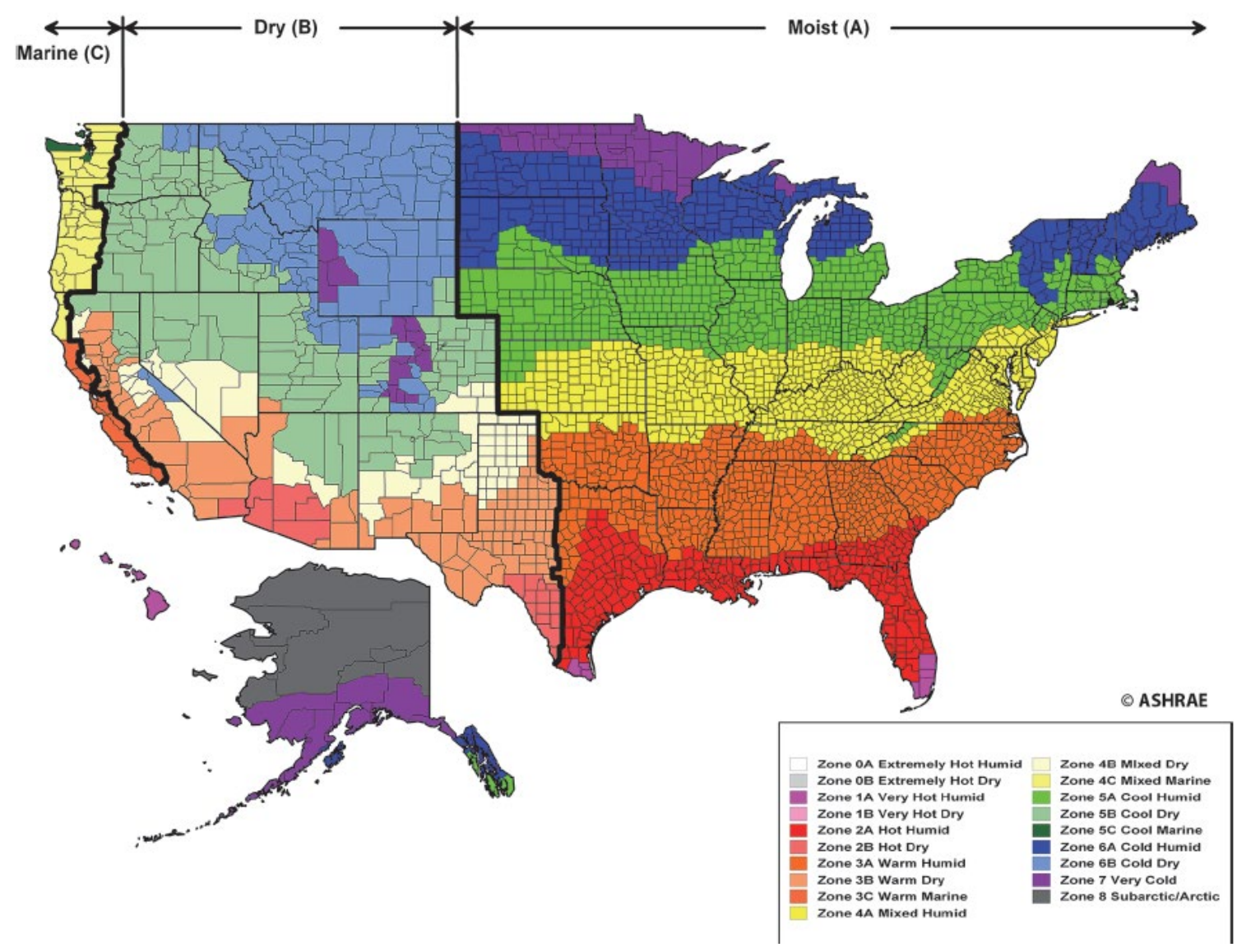

Figure A-1. IECC Climate Zone Map (ASHRAE 2013) 


\section{Company A}

\section{Set 1}

Table A-1 shows the distribution of RTU cooling capacity at the pharmacy sites.

Table A-1. Distribution of Rooftop Unit Capacity at the Pharmacy Sites

\begin{tabular}{|c|c|}
\hline Capacity (tons) & Quantity \\
\hline 2 & 1 \\
\hline 2.5 & 1 \\
\hline 3 & 15 \\
\hline 4 & 3 \\
\hline 5 & 27 \\
\hline 6 & 4 \\
\hline 7.5 & 12 \\
\hline 10 & 6 \\
\hline 12.5 & 4 \\
\hline 15 & 24 \\
\hline 17.5 & 27 \\
\hline 20 & 9 \\
\hline
\end{tabular}




\section{Set 2}

Table A-2 shows the distribution of RTU cooling capacity at the clothing retail sites. There are significantly more units with capacities between 10 and 20 tons.

Table A-2. Distribution of Rooftop Unit Capacity at the Clothing Retail Sites

\begin{tabular}{|c|c|}
\hline Capacity (tons) & Quantity \\
\hline 3.5 & 2 \\
\hline 4 & 25 \\
\hline 5 & 48 \\
\hline 6 & 37 \\
\hline 7.5 & 137 \\
\hline 8 & 7 \\
\hline 8.5 & 37 \\
\hline 10 & 314 \\
\hline 12.5 & 236 \\
\hline 15 & 309 \\
\hline 17.5 & 122 \\
\hline 18 & 1 \\
\hline 20 & 271 \\
\hline 25 & 97 \\
\hline 27.5 & 4 \\
\hline 30 & 14 \\
\hline 35 & 4 \\
\hline 40 & 6 \\
\hline 50 & 10 \\
\hline 55 & 2 \\
\hline 60 & 4 \\
\hline 75 & 1 \\
\hline 125 & 1 \\
\hline
\end{tabular}

